\title{
Expert consensus for the diagnosis and treatment of patient with hyperuricemia and high cardiovascular risk
}

\author{
Claudio Borghi ${ }^{1}$, Andrzej Tykarski ${ }^{2}$, Krystyna Widecka ${ }^{3}$, Krzysztof J. Filipiak ${ }^{4}$, \\ Justyna Domienik-Karłowicz ${ }^{5,6}$, Katarzyna Kostka-Jeziorny ${ }^{2,6}$, Albert Varga ${ }^{7}$, \\ Milosz Jaguszewski ${ }^{6,8}$, Krzysztof Narkiewicz ${ }^{9}$, Giuseppe Mancia ${ }^{10}$ \\ ${ }^{1}$ Department of Medical and Surgical Sciences, University of Bologna, Italy \\ ${ }^{2}$ Department of Hypertension, Angiology and Internal Diseases, \\ Poznan University of Medical Sciences, Poznan, Poland \\ ${ }^{3}$ Department of Hypertension and Internal Medicine, Pomeranian Medical University, Szczecin, Poland \\ ${ }^{4}$ First Department of Cardiology, Medical University of Warsaw, Poland \\ ${ }^{5}$ Department of Internal Medicine and Cardiology with the Center for Diagnosis and Treatment \\ of Venous Thromboembolism, Medical University of Warsaw, Poland \\ ${ }^{6}$ Club 30, Polish Cardiac Society, Poland \\ ${ }^{7}$ Institute of Family Medicine, University of Szeged, Hungary \\ ${ }^{8}$ First Department of Cardiology, Medical University of Gdansk, Poland \\ ${ }^{9}$ Department of Hypertension and Diabetology, Medical University of Gdansk, Poland \\ ${ }^{10}$ Università Milano-Bicocca, Milan, Italy
}

\section{Definition and epidemiology: The burden of hyperuricemia is rising}

The definition of hyperuricemia (HU) varies widely in different studies, which makes the epidemiological reports somewhat inconsistent. HU remains the culprit of the pathogenesis of gout which occurs in 3-6\% of men and 1-2\% of women from Western countries [1]. The linear relationship between serum uric acid (sUA) levels and the risk of gout have been demonstrated in many studies and registries including the large-scale Framingham study and Normative Aging study in the United States of America (USA) [1]. The United States National Health and Nutrition Examination Survey (NHANES) study estimated the prevalence of gout to be $3.9 \%$ (5.9\% for men, $2.0 \%$ for women) and the HU prevalence to be $21.4 \%$ (21.2\% for men and $21.6 \%$ for women) [2].

The prevalence of HU depends on sex age and ethnicity, reaching a plateau at the age of 70 . At variance from USA and other Western countries (see above) in developing countries, it occurs in less than $1 \%$ of the general population, but this may represent an underestimation of the true prevalence due to insufficient epidemiological data [3] and a very high prevalence has been found in some developing subsets of the population, such as, for example, the Taiwanese aboriginals (41\%). Reports are also available of ethnic difference such as, in the USA, a higher prevalence among African Americans than among non-African Americans (25.7\%, 22.1\%, respectively) [4]. Over the 10 years, epidemiological data consistently show an increase in the prevalence of both HU and gout. This might be caused by rapid economic development and a change of dietary habits and lifestyle and among patients with a higher socioeconomic status $[5,6]$. Interestingly, sUA levels are higher in subsets of subjects at high cardiovascular (CV) risk, including postmenopausal women, non-white patients with hypertension or chronic kidney disease (CKD). The adoption of western lifestyle by natives of other countries and cultures together with a change in the socioeconomic background through immigration to Western countries, as well

Address for correspondence: Milosz J. Jaguszewski, First Department of Cardiology, Medical University of Gdansk, ul. Dębinki 7, 80-952 Gdańsk, Poland, e-mail: mjaguszewski@escardio.com.pl 
as movements from rural to urban communities, has influenced sUA levels [7, 8]. Currently, $>1.2$ million patients in the USA and United Kingdom are being prescribed allopurinol, the xanthine oxidase inhibitor (XOI), which successfully lowers their sUA level [9].

\section{The relationship between hyperuricemia and gout}

Although the definition of asymptomatic HU is still being discussed, it is after all merely, a biochemical disorder. Gout is a chronic disease with periods of inflammation, also known as flares, which are caused by the deposition of monosodium urate (MSU) crystals as a result of HU [10]. The crystallization of MSU in vitro takes place at a concentration of $\geq 6.8 \mathrm{mg} / \mathrm{dL}$ (temperature of $37^{\circ} \mathrm{C}$ ) or $>6.0 \mathrm{mg} / \mathrm{dL}$ (temperature of $35^{\circ} \mathrm{C}$ ) sUA at $\mathrm{pH}$ 7.0. This process may occur at a lower sUA concentration at lower $\mathrm{pH}$ levels and at a lower tissue temperature in peripheral joints. The resolution of tophaceous deposits occurs when sUA level is $<5 \mathrm{mg} / \mathrm{dL}$ [11]. Subsequently, the host's inflammation response to the deposited crystals shows clinical symptoms of gout [12].

Although the presence of $\mathrm{HU}$ is essential for the formation of crystals, only part of the patient population with HU develop gout i.e. $2-36 \%$ of patients in studies with a $5-10$-year period of follow-up [13, 14]. Thus, the finding of HU is not sufficient to diagnose gout. Conversely, Schlesinger et al. [15], confirmed a "true" normal sUA level $(\leq 6 \mathrm{mg} / \mathrm{dL})$ in $14 \%$ of patients suffering from an acute attack of gout. Interestingly, gout is unlikely in patients with a low sUA level, even when a confirmed normal sUA level occurs during an acute flare [16]. This indicates a more complex relationship between sUA levels and gout flares. Thus, the definition based on the solubility of UA may need to be fundamentally reconsidered [4].

High sUA levels are predominantly caused by an insufficient elimination $(90 \%)$ or overproduction $(10 \%)$ of sUA. Therefore, the aim of the treatment is dissolution and prevention of further formation of MSU crystals.

Since different mechanisms interact with the pathogenesis of gout, the clinical presentation of the disease is heterogeneous. This includes the genesis of elevated sUA, the process of crystal formation and growth, and subsequent inflammation, activated by MSU crystals. In fact, four stages can be distinguished in the development of gout: i) HU without symptoms of MSU deposition; ii) deposition of MSU crystals without symptomatic gout; iii) deposition of MSU crystals with acute exacerbations of gout; iv) advanced gout characterized by the occurrence of gouty nodules (the effect of an organized, chronic inflammatory reaction involving interleukin $1 \beta$, TNF- $\alpha$, and TGF- $\beta 1$ ), chronic arthritis and joint damage identified in radiological reports. In the absence of adequate treatment, advanced gout usually appears approximately 10 years after the first "flare-up". This mostly occurs in the distal part of the lower limb (i.e., first metatarsophalangeal joint), and undergoes spontaneous resolution within 1-2 weeks. In the absence of adequate treatment, flares occur more frequently affecting more and more joints. Ultimately the disease changes to stage 4 with the onset of tophi and joint inflammation [17].

A large body of evidence describes the link between HU, CKD and cardiovascular disease (CVD). Undoubtedly, cardiovascular and renal comorbidities play a key role in the management strategies of patients with $\mathrm{HU}$ and gout.

\section{The pathophysiological effect of HU on CVD: Purine catabolism, oxidative metabolism, inflammation, "uric acid paradox"}

The primary baseline risk factor for $\mathrm{HU}$ in patients is a mutational inactivation of a gene for uricase, an enzyme which degrades urate to the more soluble allantoin [18]. Notwithstanding, to generate $\mathrm{HU}$, additional risk factors are required.

First and foremost, an increased sUA level is the result of a purine/fructose-rich diet, genetic or environmental factors, metabolic disorders, as well as its endogenous overproduction or, in most cases, by insufficient excretion (Fig. 1). The synthesis is mainly affected by phoribosyl-pyrophosphate synthetase or purine salvage pathway influenced by hypoxanthine-xanthine phosphoribosyl transferase. Fructose causes mostly the depletion of ATP increasing the generation and release of UA [19]. An excessive purine turnover may be present in some clinical scenarios, comprised of leukemias, hemolytic anemias, etc. On the other hand, ca. $90 \%$ of UA is reabsorbed in the proximal tubular cells by urate-anion transporter 1 (URAT-1) and organic anion transporters (OATs) clustered in the renal cortex according to their roles as reuptake- or secretory transporters (Fig. 2) [20,21]. The natural mechanism of further breakdown of UA is impossible due to the lack of human uricase (hominids lost expression of gene encoding, therefore, they 


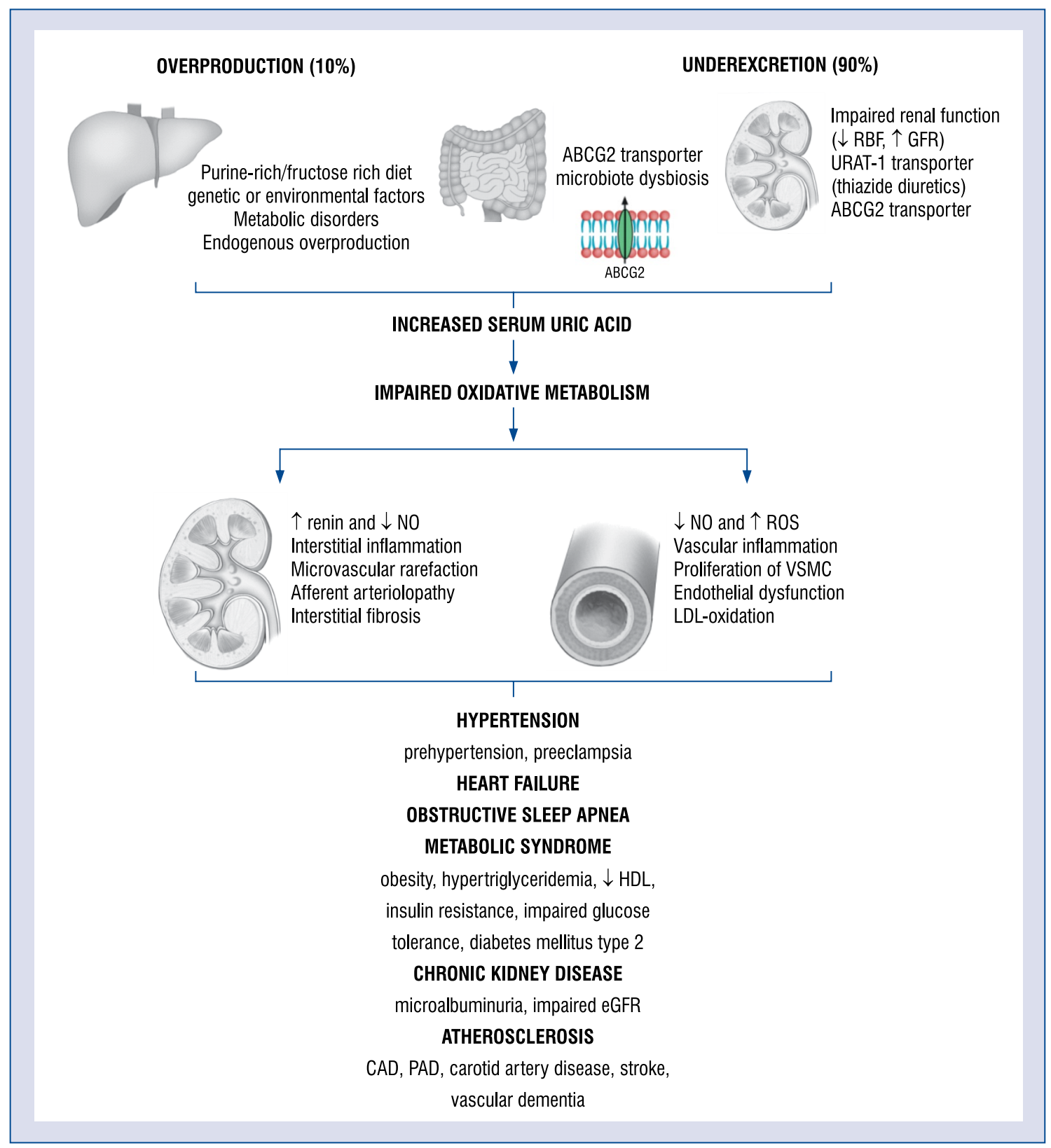

Figure 1. Pathophysiological aspects of hyperuricemia and its influence on cardiovascular and kidney disease; ABCG2 - ATP binding cassette multidrug transporter; CAD - coronary artery disease; eGFR — estimated glomerular filtration rate; HDL — high density lipoprotein; LDL — low density lipoprotein; NO — nitric oxide; PAD — peripheral arterial disease; ROS — reactive oxygen species; RBF — renal blood flow; URAT-1 — uric acid transporter 1; VSMC - vascular smooth muscle cells.

cannot convert UA to allantoin) [22]. Thus, it is the kidneys that may play a key role in the process of underexcretion.

\section{Impaired oxidative mechanism}

The increased activity of xanthine oxidase (XO) influences the XO-derived reactive oxygen species (ROS) formation resulting in vascular endothelial dysfunction. This is the case when an increased catabolism of purines and subsequent UA production xanthine oxidoreductase converts intensively hypoxanthine to xanthine and xanthine to UA. Xanthine oxidoreductase exists in two isoforms: xanthine dehydrogenase and XO. XO uses molecular oxygen as an electron acceptor, thus, generating superoxide anion and other reactive oxygen species as by-products which can trigger endothelial dysfunction (e.g. reduces endothe- 


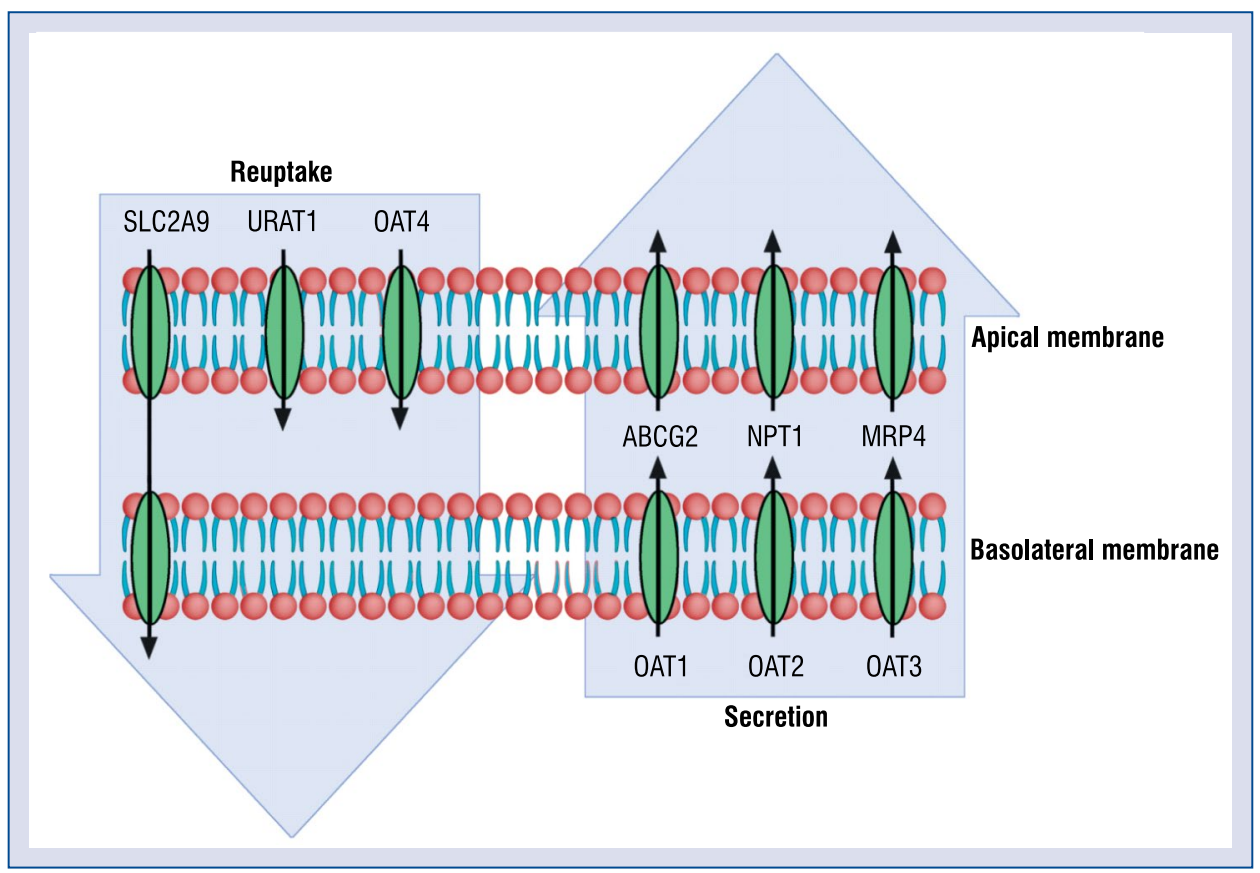

Figure 2. Renal proximal tubule urate transportasome; ABCG2 - ATP binding cassette multidrug transporter; OAT — organic anion transporter; URAT-1 - uric acid transporter 1.

lial nitric oxide [NO] production) and thereby contribute to the incidence of hypertension and target organ damage. Circulating and endothelialbound XO is over-expressed in ischemic tissues. Oxidative stress generated by $\mathrm{XO}$ overactivity has a detrimental effect on the vascular endothelium including coronary arteries [23, 24]. Thus, increased sUA levels impair an oxidative metabolism, stimulating the renin-angiotensin system and inhibits the release of endothelial NO. This contributes to, microvascular damage to afferent arterioles, renal vasoconstriction and, permanent sodiumsensitive hypertension [25, 26]. Persistent renal vasoconstriction may contribute to arteriolosclerosis and the development of primary hypertension. Indeed, in many experimental studies, UA induces vascular smooth-muscle cell (VSMC) proliferation, inflammation processes, oxidative stress and, consequently, local renin-angiotensin system activity [27-29]. Whether hypertension exists or not, the influence of an increased level of sUA on endothelial cells and VSMC develops microvascular renal disease [28, 30, 31]. On one hand, preglomerular arteriolar disease impairs renal autoregulatory response and glomerular hypertension. On the other in diabetic patients, elevated sUA levels are a well-known predictor of microalbuminuria and renal dysfunction [32, 33] being associated with an impaired glomerular filtration rate (GFR) [34].
Lastly, preclinical research supports the hypothesis that both endothelial dysfunction and the inflammatory and oxidative changes in adipocytes which remain the key factors in causing metabolic syndrome [35]. Some studies reported an association between sUA levels, obesity, and insulin resistance. Subsequently, HU has even been proposed, as a component of metabolic syndrome [36]. Although UA has an inflammatory and prooxidative effect on vascular cells and adipocytes, in some neurologic disorders, i.e., multiple sclerosis or Parkinson's disease, it may function as an antioxidant thus being protective. Many scientists focus on low-grade systemic inflammation, $\mathrm{XO}$ activity, or the unfavorable effects of HU [37], however, the entire mechanism that links these diseases is not fully understood.

\section{Genetics and the environment: Individualized diagnosis and care strategy. Key advances in the understanding of factors associated with an increased risk of $\mathrm{HU}$}

In the development of HU, the influence of genetics and environmental factors, cannot be ignored [38]. The inheritance of sUA levels and the fractional excretion of urate have been reported in studies which examine the phenotypic relationship between twins and establish it as $43-73 \%$ and 
46-96\%, respectively [38, 39]. Indeed, genome-wide association studies identified the genetic basis of $\mathrm{HU}$ as dominated by loci containing urate transporters and interacting proteins involved in the excretion of urate (SLC2A9, ABCG2, SLC22A11, SLC17A1-SLC17A4 and PDZK1) and proteins associated with metabolic pathways (e.g. GCKR, A1CF, IGF1R). For instance, reduced intestinal excretion is associated with polymorphisms of the ABCG2 gene [40]. Consequently, some research has shown a relationship between a genetic risk score of a high sUA and CV death or renal function [41, 42]. In other studies, a different SNP in the SLC2A9 gene was associated with an increased sUA level and normal blood pressure (BP) or hypertension $[43,44]$. Since sUA is a result of the effects of inherited genetic variation especially on kidneys, gastrointestinal tracts and/or the liver and different processes, further specialized genome-wide association studies is required.

Currently, the explanation of the genetic impact on the development of gout from HU is still insufficient. First and foremost, genes encoding proteins are involved in the NLRP3 (NOD-, LRR- and pyrin domain-containing 3) inflammasome pathway feature [45]. The genetic effect depending on glycolysis genes as well as the interactions between genes and environmental factors - i.e., diuretics, alcohol - have already been researched. Interestingly, genome-wide and targeted sequencing revealed the population-specific and penetrant genetic variants. Which have provided insight into the pathogenesis of gout, as well as the prediction of likely responsiveness to urine-lowering therapy [45]. These advances lead to individualized patient care. Genetic data can inform about the prognosis in patients suffering from HU, and help clinicians in their selection and dosage of urate-lowering therapy (ULT) and the correct advice on lifestyle changes.

Environmental factors that influence $\mathrm{HU}$ include diet and medication: i.e. probenecid, benzbromarone and sulfinpyrazone and the XOI allopurinol, febuxostat, antihypertensive drugs, cholesterollowering therapy, steroid medication, some nonsteroidal anti-inflammatory drugs and antibiotics as well as small doses of acetylsalicylic acid and thiazides (Table 1). A high intake of the following: meat, seafood, fructose, alcohol, and sodium are known to increase sUA levels.

\section{Hyperuricemia and comorbidities:}

\section{A high sUA level and cardiovascular risk}

Uric acid remains an end-product of purine catabolism and is considered, an independent factor
Table 1. Drug effect on the serum level of uric acid [4].

\begin{tabular}{ll}
\hline Acetylsalicylic acid & $\uparrow$ (at low doses) \\
& $\downarrow$ (at high doses) \\
Clopidogrel & $\leftrightarrow$ \\
Ticagrelor & $\uparrow$ \\
Beta-blockers (propranolol, & $\uparrow$ \\
atenolol, metoprolol, timolol) & \\
ACEls and ARBs & $\leftrightarrow$ \\
Losartan & $\downarrow$ \\
Diuretics (loop diuretics, & $\uparrow$ \\
thiazide-type diuretics, & \\
amiloride, triamterene, & \\
spironolactone, eplerenone) & \\
Alpha-blockers & $\leftrightarrow$ \\
Amlodipine & $\leftrightarrow$ \\
Fenofibrates & $\downarrow$ \\
Atorvastatin & $\downarrow$ \\
Simvastatin & $\leftrightarrow$ \\
Hypoglycemic agents & $\downarrow$ \\
SGLT2 inhibitors & \\
\hline
\end{tabular}

$\uparrow$ - increase; $\downarrow$ - decrease; ACEls — angiotensin-converting enzyme inhibitors; ARBs - angiotensin receptor blocker; SGLT2 - sodium glucose cotransporter 2

for the development of a wide variety of microvascular and macrovascular disorders: hypertension [46], metabolic syndrome [47, 48], coronary artery disease (CAD) [49], diabetes [50], cerebrovascular disease [51, 52] and CKD (Fig. 1) [53] as well as other CVDs [54, 55] and, conversely, these comorbidities increase the incidence of HU [4].

As mentioned above, the risk of crystallization of MSU increases when the saturation of sUA is > $6.8 \mathrm{mg} / \mathrm{dL}$ [18]. This induces the localized inflammatory reactions in joints and connective tissue [56] leading to gout, in up to $36 \%$ of HU-patients within a period of 5-10 years [13, 14]. However, some studies reported a relation between sUA level and CVD not only in patients with clearly diagnosed $\mathrm{HU}$, but also with values considered as normal to high, i.e. $>5.2-5.5 \mathrm{mg} / \mathrm{dL}$ [57-59]. Notably, since a high sUA concentration is associated with inflammatory markers, i.e. C-reactive protein or neutrophil count, inflammation seems to be a major link between HU and CVD and kidney diseases [4].

Patients with $\mathrm{HU}$ or gout require systematic screening for diseases associated with high sUA concentrations. A large body of evidence confirms the contribution of $\mathrm{HU}$ in the worsening of cardiovascular, diabetic, lipid and renal diseases [41, $60,61]$. Thereby supporting the evidence that an increased sUA level indicates an emerging $\mathrm{CV}$ 
Table 2. Diseases associated with hyperuricemia, requiring clinical evaluation in patients diagnosed with hyperuricemia.

Excessive alcohol consumption, lead poisoning
Lipid disorders, modifiable risk factors for
coronary disease/stroke
Use of drugs increasing serum uric acid
Obesity
Metabolic syndrome, type 2 diabetes
Kidney stones in past medical history
Chronic kidney disease
Hypertension

risk $[62,63]$. Therefore, the management of such conditions should be an integral part of a patients' treatment strategy (Tables 2 and 3) [4, 64-66].

In the NHANES, which included 5707 participants aged 20 years and above, hypertension was diagnosed in $74 \%$ of patients, CKD in $71 \%$, obesity (body mass index [BMI] $\geq 30 \mathrm{~kg} / \mathrm{m}^{2}$ ) in $53 \%$, type 2 diabetes in $26 \%$, nephrolithiasis in $24 \%$, past myocardial infarction (MI) in $14 \%$, chronic heart failure (HF) in $11 \%$, had suffered a stroke $10 \%$ [67]. The negative results mentioned above were more frequent in patients with $\mathrm{HU}$ than in patients without. In the group of patients with a sUA level of $>10 \mathrm{mg} / \mathrm{dL}$, these conditions were even more frequent, i.e.: $86 \%$ of patients suffered from chronic disease, $66 \%$ hypertension, $65 \%$ obesity, $33 \% \mathrm{HF}$, $33 \%$ type 2 diabetes, $23 \%$ past MI, and $12 \%$ had suffered a stroke in the past.

\section{Hyperuricemia and hypertension}

It has been known for a while, that renal injury can be caused by advanced arteriosclerosis, glomerulosclerosis, interstitial fibrosis, i.e. a deposition of urate crystal. This was reflected in a majority of patients with HU/gout who suffered from hypertension and were in an older age group [68]. One of the hypothesis attributes HU in hypertension to an impaired urate clearance and tubular secretion [69] as a result of a reduced renal blood flow [70] with an impaired delivery of urate to the sites of tubular secretion in the peritubular space. Nevertheless, recent preclinical and clinical studies consistently support the hypothesis that increased levels of sUA may lead to hypertension [27, 50, 71-82]. Remarkably, $\mathrm{HU}$ is more frequent in primary hypertension vs. white-coat or secondary hypertension [57]. Moreover, it is common among patients with prehypertension or microalbuminuria [32, 83].

An ample body of evidence widely acknowledged that the association between an increase in the relative risk of hypertension and high levels of sUA remains independent of traditional risk factors $[77,79,84-90]$. Interestingly, the association between sUA, hypertension and CVD remain stronger in women, younger patients, and patients with fewer CV risk factors [4]. In a large meta-analysis involving 18 studies $(\mathrm{n}=55,607)$, Grayson et al. [84] confirmed that there is an increase of $13 \%$ in the incidence of new-onset hypertension for every increase of $1 \%$ in sUA level. Kubawara et al. [91] in their retrospective cohort

Table 3. Prevalence of comorbidities according to hyperuricemia and gout in National Health and Nutrition Examination Survey (NHANES US) 2007-2008 [67].

\begin{tabular}{lcc}
\hline Comorbidities & \multicolumn{2}{c}{ Hyperuricemia } \\
\cline { 2 - 3 } & $\begin{array}{c}\text { Gout } \\
\text { Prevalence, \% (95\% CI) }\end{array}$ & $\begin{array}{c}\text { No gout } \\
\text { Prevalence, \% (95\% CI) }\end{array}$ \\
\hline Hypertension & $77.7(66.6-88.8)$ & $47.2(43.0-51.4)$ \\
CKD stage $\geq 2$ & $71.8(61.3-82.3)$ & $70.4(62.8-78.0)$ \\
Obesity - BMI $30 \mathrm{~kg} / \mathrm{m}^{2}$ & $55.6(45.5-65.7)$ & $54.2(49.0-59.4)$ \\
Diabetes & $26.9(9.7-44.1)$ & $12.2(8.7-15.6)$ \\
CKD stage $\geq 3$ & $22.6(14.0-31.2)$ & $17.4(13.2-21.5)$ \\
Nephrolithiasis & $20.2(10.3-30.2)$ & $11.6(8.9-14.3)$ \\
Stroke & $11.8(0.4-23.1)$ & $5.1(3.6-6.7)$ \\
Heart failure & $11.7(6.1-17.4)$ & $4.5(3.4-5.5)$ \\
Myocardial infarction & $11.6(4.5-18.7)$ & $4.5(3.3-5.6)$ \\
\hline
\end{tabular}

Depicted are n prevalence (\%) and 95\% confidence interval (CI).

$\mathrm{BMI}$ - body mass index; CKD — chronic kidney disease; GFR - glomerular filtration rate

$\mathrm{CKD}$ stage $\geq 2=\mathrm{GFR}<60 \mathrm{~mL} / \mathrm{min} / 1.73 \mathrm{~m}^{2}$ and $\geq 30 \mathrm{~mL} / \mathrm{min} / 1.73 \mathrm{~m}^{2} ; \mathrm{CKD}$ stage $\geq 3=\mathrm{GFR}<30 \mathrm{~mL} / \mathrm{min} / 1.73 \mathrm{~m}{ }^{2}$ and $\geq 15 \mathrm{~mL} / \mathrm{min} / 1.73 \mathrm{~m}{ }^{2}$ 
study $(\mathrm{n}=3584)$ reported sUA level as a strong risk marker for the development of hypertension from prehypertension. The cumulative incidence of hypertension from prehypertension over 5 years was $25.3 \%$, and the cumulative incidence of hypertension in subjects with $\mathrm{HU}(\mathrm{n}=726)$ was significantly higher than in those without $\mathrm{HU}$ $(\mathrm{n}=2858 ; 30.7 \%$ vs. $24.0 \%$; $\mathrm{p}<0.001)$. In the Pressioni Arteriose Monitorate e Loro Associazioni (PAMELA) study, 2045 participants underwent a complex assessment of $\mathrm{CV}$ risk which included sUA level, metabolic, renal and anthropometric variables, left ventricular (LV) mass index, as well as the measurement of, home, office, and ambulatory BP. Patients were monitored for an average of 16 years. The new-onset of hypertension was recognized in patients with systolic $\mathrm{BP}(\mathrm{SBP})$ or diastolic BP (DBP) exceeding the upper normality levels. On subsequent examination or after introducing antihypertensive therapy an increase of sUA by $1 \mathrm{mg} / \mathrm{dL}$ was associated with a significant increase in the risk of developing new-onset home and ambulatory hypertension (odds ratio [OR] 1.34, 95\% confidence interval (CI) 1.06-1.7, $\mathrm{p}=0.015$; OR 1.29, 95\% CI 1.05-1.57, $\mathrm{p}=0.014$, respectively) [85]. Notably, this was the first study to include a measurement of sUA level among the factors included in the algorithm assessing the total CV risk [61].

\section{Hyperuricemia and metabolic syndrome}

As mentioned above, several studies demonstrated that sUA level is associated with metabolic syndrome, high BMI, waist circumference, high fasting blood glucose levels, and dyslipidemia [92]. These results, and the fact that targeting high levels of serum low-density lipoprotein (LDL) is beneficial for patients at $\mathrm{CV}$ risk prompted other groups to investigate whether HU predicts an increase in LDL cholesterol. Actually, Kuwabara et al. [61] confirmed that elevated sUA increased the risk of developing high LDL cholesterol in both men (OR 1.159 per $1 \mathrm{mg} / \mathrm{dL}$ increase, $95 \%$ CI 1.009-1.331, $\mathrm{p}=0.037$ ) and women (OR 1.215, $95 \%$ CI 1.061-1.390, $\mathrm{p}=0.005$ ), as well as hypertriglyceridemia.

Hyperuricemia and chronic kidney disease: "What comes first?"

First observations of the possible causative role of sUA on CKD were confirmed in large studies, including, the NHANES and the German Chronic Kidney Disease (GCKD) study [93, 94]. Data from the German registry documented gout in
$24.3 \%$ of patients with CKD. The prevalence of gout was substantially higher in patients with estimated GFR (eGFR) of $<30 \mathrm{~mL} / \mathrm{min} / 1.73 \mathrm{~m}^{2}$ vs. $\geq 60 \mathrm{~mL} /$ $/ \mathrm{min} / 1.73 \mathrm{~m}^{2}$ [94]. The meta-analysis, which included 18 prospective studies $(n=431,000)$, revealed that $\mathrm{HU}$ predicts the occurrence of CKD and GFR decline [95]. Indeed, HU plays a key role in the development and progression of CKD. It remains an independent factor in the progression of CKD, even after making adjustment for classic comorbidities such as hypertension, proteinuria, and dyslipidemia. This relationship was confirmed in IgA nephropathy, diabetes nephropathy, renal transplantation, or autosomaldominant polycystic kidney disease [96-99]. Notably, in normotensive patients, with normal renal function, the association between sUA and the likelihood of a decrease in eGFR was noted. This effect was apparent at a concentration level of sUA of $5.5 \mathrm{mg} / \mathrm{dl}$, $5.0 \mathrm{mg} / \mathrm{dL}$ in women [100].

Since the pathogenesis of $\mathrm{HU}$ is complex and lots of conflicting factors influencing CKD are well described, the question "what comes first?" remains open [95]. It is worth noting, that hypertension can cause $\mathrm{CKD}$ and, subsequently, there is a decline in renal function. Moreover, the diuretic therapy may essentially increase the sUA levels. However, the studies based on healthy subsets revealed a clear association between sUA and CKD in long-term observation [53, 101].

\section{"Uric acid paradox"}

Despite the well-known association between $\mathrm{HU}$ and CAD, high sUA levels are strongly associated with peripheral carotid vascular disease and vascular dementia [51, 102].

In a study by Ruggiero et al. [103] $(\mathrm{n}=1016)$, it was found that elderly patients with dementia had higher concentrations of sUA. Patients with the highest sUA concentrations had a higher probability to develop dementia (OR 3.32, 95\% CI 1.06-10.42) [103]. Contrarily, some studies revealed that HU might reduce the risk of neurological diseases, especially Parkinson's and Alzheimer's disease, vascular and non-vascular dementia [104] or osteoporosis [105]. This so-called "uric acid paradox" has already been widely discussed [4].

\section{Hyperuricemia and adverse events: A high sUA level and its influence on cardiovascular outcome}

\section{Hyperuricemia and mortality}

The Third NHANES presented an increased risk of all-cause death and cardiac death in 
patients with an increased sUA level. The association remained significant even after adjustment for different factors including demography and comorbidities [106]. In the PAMELA study, patients were randomly recruited from the general population and underwent a thorough assessment of CV risk, including an echocardiogram and out-of-office BP measurement. The analysis suggested that the cut-off sUA level which showed the best trade-off between sensitivity and specificity of risk prediction were $5.4 \mathrm{mg} / \mathrm{dL}$ for CV mortality and $4.9 \mathrm{mg} / \mathrm{dL}$ for all-cause mortality [85]. Data from the Preventive Cardiology Information System (PreCIS) database documented that for each $1-\mathrm{mg} / \mathrm{dL}$ increase in the sUA level, there was a $39 \%$ increase in the risk of death. After adjusting for age, sex, weight, BMI, waist circumference, $\mathrm{BP}$, history of CVD, eGFR rate, levels of cholesterol fractions, and plasma glucose levels, smoking status, and alcohol consumption, the sUA level continued to accurately predict the risk of death (hazard ratio [HR] 1.26, 95\% CI 1.15-1.38, $\mathrm{p}<0.001)$. Notably, the association occurred whether the patient was taking diuretics or not.

Interestingly, sUA level significantly improved the predictive accuracy of a model that included Framingham Heart Study score factors, components of metabolic syndrome, and fibrinogen level [107]. In a group of 51,297 male patients included in the Health Professionals Follow-Up Study, those suffering from gout had a higher risk of all-cause death. Curiously, among men without preexisting $\mathrm{CAD}$, the increased mortality risk was primarily a result of an elevated risk of CVD death. Additionally, men with gout had a higher risk of nonfatal MI than men without gout (relative risk [RR] 1.59; 95\% CI 1.04-2.41) [108]. In a much larger study that included 354,110 subjects without a history of gout at the Chang Gung Memorial Hospital in Taiwan, patients with both high and low sUA levels were at higher risk of all-cause and cardiovascular mortality [109]. The increased risk of death was reported among patients with a high sUA level and $\mathrm{HF}$ [110]. A large retrospective analysis of patients with symptomatic $\mathrm{HF}$ revealed that $\mathrm{HU}$ was significantly associated with increased HF events or death [111].

\section{Hyperuricemia and acute myocardial infarction and risk of strokes}

Krishnan et al. [112] confirmed the independent risk relationship between HU and acute MI. Interestingly, gouty arthritis was associated with an excess risk of acute MI, which was not explained by its well-known links with other comorbidities, i.e., renal function, metabolic syndrome, traditional $\mathrm{CV}$ risk factors as well as diuretic therapy. These results have prompted further research in which sUA levels and untreated gout were documented as independent prognostic markers for poor all-cause and cardiac mortality in patients with recent acute MI [112].

In the Rotterdam Study ( $\mathrm{n}=4385)$, among patients without a history of MI or who had suffered strokes at baseline, high sUA levels were associated with long-term risk of MI and strokes; an age and sex-adjusted hazard ratios (95\% CI) for highest versus lowest quintile of sUA were 1.68 (1.24-2.27) for CVD, 1.87 (1.12-3.13) for MI, 1.57 (1.11-2.22) for strokes, $1.77(1.10-2.83)$ for ischemic strokes, and $1.68(0.68-4.15)$ for hemorrhagic strokes [102]. Tscharre et al. [113] suggest an independent association of $\mathrm{HU}$ (defined as UA levels $>6.0 \mathrm{mg} / \mathrm{dl}$ in women, and $>7.0 \mathrm{mg} / \mathrm{dl}$ in men) with long-term major adverse cardiovascular event (MACE), including CV death, MI and strokes, in acute coronary syndrome patients undergoing percutaneous coronary intervention. Patients with HU had a 1.6-fold increased RR for CV death $(\mathrm{p}=0.005)$ and a 1.5 -fold increased risk for MI $(\mathrm{p}=0.032)$ [113]. In a small study $(\mathrm{n}=140)$, the prevalence of moderate-to-severe coronary calcification in CAD was more severe in hyperuricemic patients with asymptomatic MSU crystal deposition than normouricemic or hyperuricemic patients without such deposits [114].

In an analysis of the large Swedish registry (n $=417,734$ ) of a group of patients undergoing health check-ups, moderate levels of sUA appeared to be associated with an increased incidence of acute MI, stroke and congestive HF in middle-aged subjects without prior CVD [115]. Finally, sUA level was positively associated with the presence $(\mathrm{p}=0.0001)$, the number $(\mathrm{p}=0.001)$, the size $(\mathrm{p}=0.001)$, and the location of lacunar infarcts (LI) in the basal ganglia $(\mathrm{p}=0.0038)$, the deep white matter $(\mathrm{DWM})$ $(\mathrm{p}<0.0001)$, and the pons $(\mathrm{p}=0.0156)$. Pathologically, it was characterized by arteriolosclerosis and atherosclerosis. Interestingly, the occurrence of LI increased starting from sUA levels of $5.7 \mathrm{mg} / \mathrm{dl}$ [116]. HU may substantially increase the risk of a stroke, even in patients at a low risk of atrial fibrillation, thus, may constitute an independent risk factor for strokes in a hyperuricemic setting.

\section{Hyperuricemia treatment and cardiovascular outcomes: Allopurinol and febuxostat}

Xantine-oxidase inhibitors, especially allopurinol, are currently recommended as a first-line 
ULT. However, the optimism related to febuxostat has been dispelled by recently published results from the Cardiovascular Safety of Febuxostat and Allopurinol in Patients with Gout and Cardiovascular Morbidities (CARES) study [117].

\section{Allopurinol: The influence of XOI on cardiovascular outcomes}

\section{Allopurinol and mortality}

Knowledge of the effectiveness of XOI makes them a subject of major interest [118-126]. However, the causality between HU/gout and these $\mathrm{CV}$ outcomes remains controversial, mainly due to confounding variables and common etiological factors [4, 126-128].

The effect of purine XOI on all-cause mortality and $\mathrm{CV}$ mortality is probably due to its potent antioxidant effect, which has the ability to inhibit reactive oxygen species production $[129,130]$. Among potential mechanisms, it should be stressed that endothelial dysfunction and low-grade inflammation can occur as a major negative factor $[7,131]$. Of note, at high concentrations, XO promotes oxidative stress and emphasizes endothelial dysfunction. Increasing evidence exists to suggest the crucial role of XO in various forms of ischemic and other types of tissue and vascular injury, inflammatory processes and chronic HF [132].

In a record-linkage database $(\mathrm{n}=7135), \mathrm{CV}$ event rates were 74.0 (95\% CI 61.9-86.1)/1000-person-years in the $100 \mathrm{mg}$ allopurinol group, 69.7 (95\% CI 49.6-89.8) in the $200 \mathrm{mg}$ allopurinol group and 47.6 (95\% CI 38.4-56.9) in the $\geq 300 \mathrm{mg}$ allopurinol group [133]. Moreover, high-dose allopurinol, defined as $\geq 300 \mathrm{mg} / \mathrm{dL}$ vs. $<299 \mathrm{mg} / \mathrm{dL}$, was associated with a reduced risk of all-cause mortality (adjusted HR 0.65, 95\% CI 0.42-0.99) $[7,134]$. In the large-scale cohort study by Dubreuil et al. [135] the initiation of allopurinol therapy was associated with an $11 \%$ lower risk of all-cause death in patients with $\mathrm{HU}$ and $19 \%$ lower risk of death in patients with gout.

\section{Allopurinol and CAD}

The key role of six-weeks treatment with allopurinol (600 mg daily) vs. placebo in a small randomized controlled trial (RCT) of 65 patients (aged 18-85 years) who had angiographically documented $\mathrm{CAD}$, a positive exercise tolerance test, and stable chronic angina pectoris showed that allopurinol vs. placebo increased the median time to ST depression to $298 \mathrm{~s}$ (interquartile range [IQR] 211-408) vs. 249 s (IQR 200-375, p = 0.0002) [136]. Simi- larly, a small, randomized, double-blind, placebo-controlled study $(\mathrm{n}=65)$ in patients with CAD and LV hypertrophy [137] proved a significant reduction of LV mass and LV end-systolic volume in patients receiving $600 \mathrm{mg}$ of allopurinol vs. placebo $(-5.2 \pm 5.8$ g vs. $-1.3 \pm 4.48 \mathrm{~g}, \mathrm{p}=0.007 ;-2.81 \pm$ $\pm 7.8 \mathrm{mls}$ vs. $+1.3 \pm 7.22 \mathrm{mls}, \mathrm{p}=0.047$, respectively) [137]. Higgins et al. [138] in a systematic review and meta-analysis of 40 studies confirmed that XOI improves endothelial function and reduces markers of oxidative stress. A steep-dose response relationship between allopurinol and endothelial function has been presented and described showing the mechanistic effect of vascular oxidative stress [139].

\section{Allopurinol and congestive $\mathrm{HF}$}

In a large observational study of patients with $\mathrm{HF}$ and a history of gout $(\mathrm{n}=25,090),>30$ day-therapy with XOI was associated with reduced readmissions to hospital, caused by HF or death (adjusted RR 0.69; 95\% CI 0.60-0.79, $\mathrm{p}<0.001$ ), and all-cause mortality (adjusted RR 0.74; 95\% CI 0.61-0.90, p < 0.001) [111]. In contrast, investigators from Oxypurinol Therapy for Congestive Heart Failure (OPT-CHF) study did not find clinical improvements in the unselected patient cohort in a group of patients $(n=405)$ with moderate-to-severe HF (New York Heart Association [NYHA] functional class III/IV) due to systolic dysfunction. Data from EXACT-HF study, involving patients $(\mathrm{n}=253)$ with symptomatic HF, left ventricular ejection fraction (LVEF) $\leq 40 \%$, receiving allopurinol (600 mg daily) for 24 weeks showed no improvement in LVEF and no significant difference in clinical status between the allopurinol- and placebotreated patients (worsened: $45 \%$ vs. $46 \%$, unchanged: $42 \%$ vs. $34 \%$, improved: $13 \%$ vs. $19 \%$, respectively; $\mathrm{p}=0.68)$ [140].

Interestingly, the post-hoc analysis from OPT-CHF suggested that sUA reduction due to oxypurinol correlated with favorable clinical response [141-144] and that sUA may serve as a biomarker to target XO inhibition in congestive HF. These results show the positive potential role of an early intervention of implementing the ULT in patients with congestive $\mathrm{HF}$.

\section{Allopurinol and hypertension}

An ample amount of studies investigated the effect of XOI on hypertension. In the United Kingdom Clinical Practice Research Datalink, allopurinol use was independently associated with a fall in both SBP and DBP [145]. In the short-term, crossover study presenting preliminary results in adolescents with newly diagnosed hypertension, 
treatment with XOI resulted in a lowering of BP. Treatment with allopurinol (200 mg twice a day for 6 weeks) vs. placebo caused a mean change in SBP $(-6.9 \mathrm{mmHg}, 95 \% \mathrm{CI}-4.5$ to $-9.3 \mathrm{mmHg}$ vs. $-2.0 \mathrm{mmHg}, 95 \%$ CI 0.3 to $-4.3 \mathrm{mmHg}, \mathrm{p}=0.009$ ) and DBP $(-5.1 \mathrm{mmHg}, 95 \% \mathrm{CI}-2.5$ to $-7.8 \mathrm{mmHg}$ vs. $-2.4 \mathrm{mmHg}, 95 \% \mathrm{CI} 0.2$ to $-4.1 \mathrm{mmHg}, \mathrm{p}=$ $=0.05$ ) [146]. In meta-analysis of 10 clinical studies with 738 participants treated with allopurinol, SBP decreased by $3.3 \mathrm{mmHg}(95 \% \mathrm{CI} 1.4-5.3 \mathrm{mmHg}$, $\mathrm{p}=0.001)$ and DBP by $1.3 \mathrm{mmHg}(95 \% \mathrm{CI} 0.1-2.5$ $\mathrm{mmHg}, \mathrm{p}=0.03$ ) [147]. These findings represent a new potentially positive therapeutic result which requires confirmation in future larger clinical trials.

Whether sUA level is a causative mediator of increased BP and impaired vascular compliance remains unclear. However, in the study of treated hypertensive patients, allopurinol increased aortic compliance irrespective of the antihypertensive drugs used [148]. This is in line with the observation that inhibition of XO with allopurinol significantly reduces arterial wave reflection measured by augmentation index, a marker of arterial stiffness in stroke survivors [149].

In a randomized, double-blinded, placebocontrolled trial, two mechanisms of sUA reduction were investigated in prehypertensive, obese, adolescents, aged 11-17 years by using XOI or probenecid. Subjects treated with ULT experienced a reduction in clinical SBP $10.2 \mathrm{mmHg}$ and DBP $9.0 \mathrm{mmHg}$. ULT also resulted in a significant reduction in systemic vascular resistance. This data indicates that, at least in young patients with prehypertension, their sUA level influences the BP and that it can be significantly reduced by ULT $[147,150]$.

In a new retrospective analysis of Survival of Myocardial Infarction Long-Term Evaluation (SMILE studies), researchers evaluated the 1-year combined occurrence of MACE, death or hospitalization for $\mathrm{CV}$ causes in patients after acute $\mathrm{MI}$ using angiotensin converting enzyme inhibitors (ACEI), such as zofenopril or captopril, plus XOI. The rate of survival free from MACE was significantly higher in a group of patients from the XOI-arm than with other ACEI with no XOI (HR 2.29, $1.06-4.91, p=0.034)$. Survival time without any events was longer in patients treated with zofenopril and XOI than in those treated with a placebo or other ACEI without XOI (log rank test, $\mathrm{p}=0.033$ ) [151]. The survival benefit of XOI therapy has been proven in another RCTs and cohort studies [152]. In a recent study published in "Hypertension" allopurinol lowered $\mathrm{BP}$ in adolescents and was associated with a significantly lower risk of both stroke (HR
$0.50,95 \%$ CI $0.32-0.80)$ and major cardiac events (HR 0.61, 95\% CI 0.43-0.87). High-dose treatment, i.e., $\geq 300 \mathrm{mg}$ daily, was associated with a lower risk of stroke (HR $0.58,95 \%$ CI $0.36-0.94$ ) and major cardiac events (HR 0.65, 95\% CI 0.46-0.93).

Summarizing, a decrease in sUA levels, achieved by treating patients with ULT, mainly XOI, has, in general, been associated with an improvement in $\mathrm{CV}$ effects and amelioration in $\mathrm{BP}$ control $[62,118]$, but further large studies are essential [128]. Nevertheless, allopurinol may also be considered in hypertensives with asymptomatic HU, particularly those at high $\mathrm{CV}$ risk. Among the drugs recommended for the treatment of co-morbidities with $\mathrm{HU}$, great attention should be paid to the key drugs that influence sUA levels (Table 1) [153-159].

\section{Allopurinol and renal function}

It has been known for a long time, that therapy with XOI might essentially improve renal function [4]. A comprehensive meta-analysis of RCTs revealed statistically significant improvement in eGFR and serum creatinine after ULT, favoring the strategy with allopurinol [160]. Goicoechea et al. [161] documented the slower progression of CKD and reduction of the rate of proteinuria in the group randomly assigned to the arm with XOI vs. placebo. Another meta-analysis confirmed that ULT decreases the risk of kidney failure events and end-stage renal disease (ESRD) by $55 \%$ (RR 0.45 , 95\% CI $0.31 \pm 0.64)$ and $41 \%$ (RR $0.59,95 \%$ CI $0.37 \pm 0.96$, respectively), compared with standard treatment or placebo [162]. Siu et al. [163] reported a decrease in sUA levels and preservation of renal function in patients treated with XOI at 12 months. The meta-analysis of 12 studies by Sampson et al. [164] $(\mathrm{n}=1187)$ in a wide range of patients revealed improved renal function by ULT at one year assessed by the reduced serum creatinine and raised eGFR. In another population-based cohort study $(\mathrm{n}=111,992)$ investigating the association between HU and renal disease, patients treated with ULT who achieved sUA level of $6 \mathrm{mg} / \mathrm{dL}$ showed a $37 \%$-outcome reduction defined as GFR reduction of $\geq 30 \%$ or endstage renal disease [165].

\section{Febuxostat: Causes more harm to cardiovascular patients than clinical benefits}

In 2009, a new drug, febuxostat, was approved by the USA Food and Drug Administration (FDA). Febuxostat is a nonpurine XOI and provides highly selective and potent inhibition of $\mathrm{XO}$ and greater 
hypouricemic activity vs. commonly used doses of allopurinol. Unexpectedly, in 2017 the FDA alerted the public that preliminary results from a safety clinical trial show an increased risk of cardiac death with febuxostat vs. allopurinol. The first reports suggested a modestly higher rate of $\mathrm{CV}$ events with febuxostat [166]. Consequently, a large-scale, intensive RCT was designed (CARES) to investigate whether febuxostat remains non-inferior to allopurinol with regard to MACE in patients with gout and high CV risk [117]. In the meantime, a meta-analysis of 35 studies did not show a significant difference between febuxostat and allopurinol in CV events (RR 1.69, 95\% CI 0.54-5.34, $\mathrm{p}=0.37$ ) [126]. Moreover, ULT with febuxostat reduced the renal decline in subjects with gout [167]. In the multicenter FEATHER study, where patients $(\mathrm{n}=467)$ were randomly assigned in a 1:1 ratio to receive febuxostat or placebo for 108 weeks, febuxostat did not mitigate the decline in kidney function in patients with stage 3 CKD and asymptomatic HU [168].

Interestingly, during the European Society of Cardiology scientific sessions in 2018 the results of FREED study were announced, where over 1000 elderly patients with HU, defined as sUA level $>7.0 \mathrm{mg} / \mathrm{dL}$ up to $9.0 \mathrm{mg} / \mathrm{dL}$, with one or more risks for cerebral, cardiovascular, or renal disease were treated with febuxostat (up to $40 \mathrm{mg}$ daily) or non-febuxostat (non-treatment or low $100 \mathrm{mg}$ daily of allopurinol). Febuxostat lowered sUA level to mean $4.5 \pm 1.5 \mathrm{mg} / \mathrm{dL}$, while non-febuxostat group achieved only $6.76 \pm 1.45 \mathrm{mg} / \mathrm{dL}$. After 3 years, $25 \%$ relative risk reduction in the composite of death to any cause, cerebrovascular disease, non-fatal CAD, HF requiring hospitalization, the arteriosclerotic disease requiring treatment, renal impairment, and atrial fibrillation was observed in febuxostat group compared to the non-febuxostat group. Febuxostat also prevented the development and progression of CKD in this study. Notably, renal impairment was the only significantly different event, at $16.2 \%$ in the febuxostat group vs. $20.5 \%$ in the control group (HR $0.745,95 \%$ CI 0.562-0.987). There was no difference in CV clinical outcomes examined separately with febuxostat vs. control treatment. Herewith we should depict that only $27 \%$ of patients in the non-febuxostat group received allopurinol and more studies are warranted to confirm these results [Kijoma S, ESC Congress 2018]. The question remains whether the mortality results of the CARES trial are due to beneficial effects of allopurinol or deleterious effects of febuxostat.
In the last report, with findings from 32 months follow up ( $n=6190)$, CARES investigators confirmed that all-cause and CV mortality were higher in the febuxostat group than in the allopurinol group (HR for death from any cause 1.22, 95\% CI 1.01-1.47; HR for CV death $1.34,95 \%$ CI 1.03-1.73) [117].

The first phase 3 RCTs, unfortunately, provided a false hope that febuxostat was safe that led to the FDA-approval. As a result, febuxostat has been prescribed to hundreds of thousands of patients over the past decade who were unaware of the potential danger. Since the last CARES report published in 2018, strong evidence has emerged that the serious CV harms of febuxostat substantially outweigh any purported clinical benefit [117]. Thus, based on CARES study, treatment with febuxostat in patients at high CV risk should not be recommended.

\section{Management strategies: Current recommendation for the treatment of patients with increased sUA levels (Fig. 3)}

The primary aim of treatment of $\mathrm{HU}$ is to lower the sUA level (STEP 1). The measurement of sUA concentration was included in routine tests by experts of both the European Society of Cardiology and European Society of Hypertension.

Our recommendation, based on the available data and a number of available guidelines, points to an optimal target of sUA level at $6 \mathrm{mg} / \mathrm{dL}$ (360 $\mu \mathrm{mol} / \mathrm{L}$ ) which is in line with the 2016 evidencebased recommendation for the management of gout of patients on ULT. Thus, sUA levels should be monitored and maintained at $<6 \mathrm{mg} / \mathrm{dL}$ [169]. It is also in accordance with the 2012 American College of Rheumatology (ACR) Guidelines, which indicate ULT for people with symptomatic HU and recommends a target sUA level of less than $360 \mu \mathrm{mol} / \mathrm{L}$ $(6 \mathrm{mg} / \mathrm{dL})$ for all patients on ULT [170]. According to the British Society for Rheumatology, gout management by rheumatologists from the United Kingdom concords well with guidelines for most audit standards. Of note, 2016 guideline points to a lower sUA target ( $<5 \mathrm{mg} / \mathrm{dL} ; 300 \mu \mathrm{mol} / \mathrm{L}$ ) for patients with severe gout in order to facilitate faster dissolution of UA crystals, especially when tophi, chronic arthropathy, or frequent attacks occur, until a total crystal dissolution and resolution of gout. Furthermore, the British Society of Rheumatology recommends a target of sUA of $<5 \mathrm{mg} / \mathrm{dL}$ for all patients with gout [171]. Notably, 


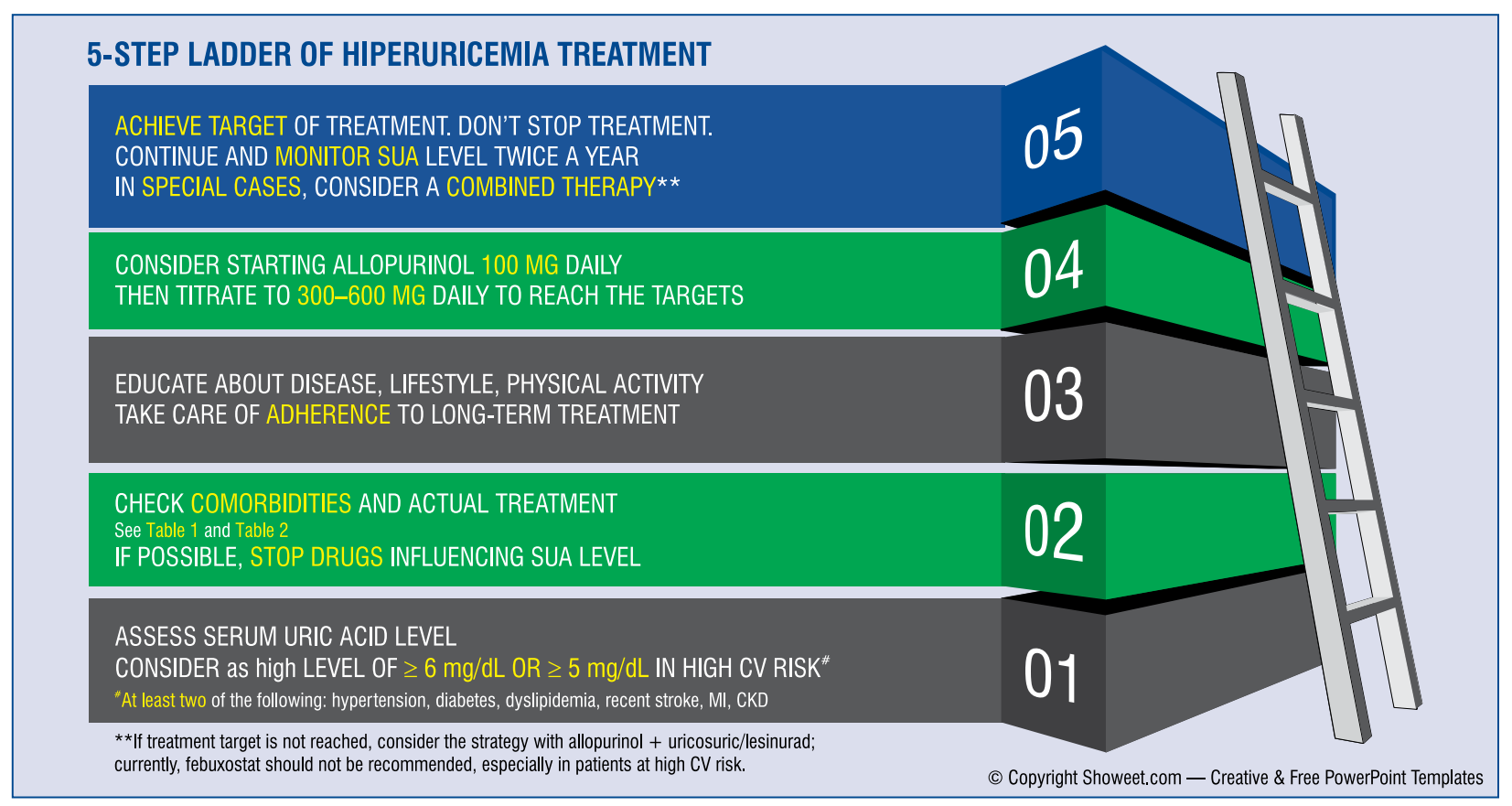

Figure 3. Management strategy for patients suffering from hiperuricemia. CV — cardiovascular; CKD — chronic kidney disease; $\mathrm{MI}$ - myocardial infarction; SUA - serum uric acid.

the PAMELA study supported the sUA level of ca. $5 \mathrm{mg} / \mathrm{dL}$ in patients at high CV risk. Thus, based on current knowledge, in our opinion, one should consider sUA target of $<5 \mathrm{mg} / \mathrm{dL}$ in patients with high $\mathrm{CV}$ risk comprising at least two of the following: hypertension, diabetes, dyslipidemia, recent stroke or MI, CKD and $<6 \mathrm{mg} / \mathrm{dL}$ for patients not suffering from the above. Still, more RCTs are needed to support this opinion.

While optimizing the management strategy of $\mathrm{HU}$, great attention should be paid to the key drugs prescribed due to comorbidities that may substantially influence sUA levels (Table 1, STEP 2). Especially since a large body of literature confirms that HU coexists with a wide variety of microvascular- and macrovascular diseases including hypertension [4], metabolic syndrome [48], CKD [53] or other CVD [54, 55] and these comorbidities increase the incidence of HU [4]. Consequently, the management of such conditions should be an integral part of a patients' treatment strategy (Table 2).

As previously reported, also in the United Kingdom, less than half of the patients treated achieved the desired sUA levels during 12 months of treatment. Desired sUA levels $\leq 6 \mathrm{mg} / \mathrm{dL}$ and $<5 \mathrm{mg} / \mathrm{dL}$ were achieved by $45 \%$ and $25 \%$ of patients, respectively [172]. In a cohort study including 6042 patients, among 1035 allopurinol users, less than half $(44.7 \%)$ reached target urate concentration [133].

Thus, we conclude that doctors often underestimated HU. An important step toward improved management of $\mathrm{HU} /$ gout in clinical routine is to improve adherence to guidelines, raising awareness of $\mathrm{HU}$ and associated comorbidities, prompting specific monitoring and treatment of these, as well as building multidisciplinary teams for optimal diagnostic and management strategy (STEP 3).

\section{Recommended life-style changes (STEP 3)}

The following dietary factors have shown an adverse effect on sUA levels: low-sodium diet [173], consumption of red meat, seafood, fructose, and sugar-sweetened beverages, alcohol [174]. Dietary factors known to decrease sUA include coffee, dairy products, cherries [155, 175], and ascorbic acid [176]. Some studies have also confirmed that weight loss and regular physical activity are effective in reducing sUA levels $[177,178]$. Therefore, maintenance of healthy weight and an increase in physical activity should be strongly recommended. Patients with a high concentration of sUA should avoid, fructose-rich and animal-derived high purine meals and alcohol. 
Xantine oxidase inhibitors:

First-line therapy (STEP 4)

As mentioned above, XOI, especially allopurinol, are recommended as a first-line ULT. They are rapidly metabolized to oxypurinol, which is eliminated by the kidneys, therefore this requires dose adjustment according to renal function [169]. According to the Summary of product characteristics of allopurinol in patients with CKD, the maximum allopurinol dosage should be adjusted to eGFR [169]. The recommended initial allopurinol dosage is $100 \mathrm{mg}$ daily, with a gradual titration, e.g. 300-600 mg daily, up to the achievement of the desired sUA target level [169].

In accordance to meta-analysis, which included 15 papers concerning allopurinol, $44.4 \%$ of patients reached the target of sUA with this therapy and the average reduction in sUA was 33.8\% [179]. If the sUA target cannot be achieved, the patient should be switched to benzbromarone with or without allopurinol (STEP 5), except in patients with eGFR of $<30 \mathrm{~mL} / \mathrm{min}$ [180]. Although there is growing evidence of a benefit of a high-dose allopurinol regimen, i.e. $\geq 600 \mathrm{mg}$ daily, especially in patients with high levels of sUA, we should still be aware of rare complications. Physicians should carefully consider dose escalation to achieve optimal treatment goals, especially due to allopurinol hypersensitivity syndrome or severe cutaneous allergic reactions (SCARs) - which usually occur after 8 weeks of therapy [181-183]. Several factors contribute to the development of this syndrome, including initial doses which are too high, CKD, accompanying use of diuretics, the presence of HLA-B*5801 [184, 185].

As mentioned above, XOI improves endothelial function [138, 186], oxidative stress markers, as well as cardiac physiology, including LVEF [187], cardiac index [187], end-systolic volume [188], and myocardial efficiency [189]. Thus, allopurinol may be considered in hypertensives with asymptomatic HU, particularly those with CVD. Although high-dose allopurinol defined as $\geq 300 \mathrm{mg} / \mathrm{dL}$ is associated with reduced risk of all-cause mortality $[7,134]$, consideration of optimal dose seems to be a major factor in the design of future research.

\section{Febuxostat}

Febuxostat, as a non-purine selective XOI, is metabolized in the liver and excreted by the kidneys. A side effect of febuxostat can be adverse skin effects. Previously, dose-adjusted febuxostat was considered in cases where the sUA target could not be achieved with allopurinol. Based on the meta-analysis of 16 papers, including febuxostat treatment, $70.3 \%$ of patients on febuxostat reached the target of sUA $(6 \mathrm{mg} / \mathrm{dL})$ and the reduction in sUA was $45.3 \%$ with respect to baseline values [179]. In first studies, febuxostat (dose of $\leq 120$ $\mathrm{mg}$ /day) resulted superior over allopurinol (dose $\leq 300 \mathrm{mg}$ /day) in terms of probability to achieve the recommended target of sUA (OR 2.64, 95\% CI 1.74-4.01) and percentage reduction of uricemia (mean difference: 13.08, 95\% CI 7.6-18.55). Furthermore, febuxostat showed better results than allopurinol in patients with CKD (OR 0.85, 95\% CI 0.75-0.97) [120, 179].

However, the safety concerns are already raised after results in patients with gout and CVD. Thus, due to substantially higher all-cause and cardiovascular mortality rate in the febuxostat group vs. as compared to in the group receiving allopurinol [117] febuxostat cannot be recommended, especially in patients at high CV risk.

\section{Lesinurad}

Lesinurad is an oral selective inhibitor of URAT1 and OAT4 renal transporters, which increases renal UA excretion and lowers sUA levels by inhibiting UA reabsorption. A dose of $200 \mathrm{mg}$ daily is recommended in combination with XOI in patients who do not achieve treatment targets. Lesinurad can increase efficiency compared to XOI applied alone or prevent maximal doses of XOI [190]. In a CLEAR study, lesinurad of $200 \mathrm{mg}$ or $400 \mathrm{mg}$ together with allopurinol significantly increased the proportion of patients who achieved the sUA target level compared to allopurinol $(54.2 \%, 59.2 \%$, and $27.9 \%$, respectively, $\mathrm{p}<0.0001)$ [191]. Similarly, the combination of lesinurad at $200 \mathrm{mg}$ and $400 \mathrm{mg}$ and maximum dose of febuxostat for 12 months compared to febuxostat monotherapy was more efficient in achieving sUA target levels in the CRYSTAL trial $[192,193]$.

To summarize, lesinurad in combination with an allopurinol is a novel option for the treatment of HU in adults with gout who have not achieved their target sUA levels with allopurinol alone [194]. Results from three clinical studies investigating the effectiveness of lesinurad suggest the addition of lesinurad to allopurinol or febuxostat is superior to XOI monotherapy in reducing sUA concentrations. However, this therapy increased the risk of renal-related adverse events. Thus, the recommendation is to use lesinurad $200 \mathrm{mg}$ orally per day, in combination with an XOI, among patients with adequate renal function (i.e., above $45 \mathrm{~mL} / \mathrm{min}$ ) in cases with inadequately controlled $\mathrm{HU}$ associated with gout, should be treated with allopurinol (STEP 5) [193]. 
Once the sUA target is achieved continuously, the dose of ULT should be maintained indefinitely with ongoing monitoring of sUA levels twice a year (STEP 5).

\section{Many unresolved questions remain: Areas in need of further study}

The prooxidant and antioxidant effect make the role of sUA complex. Furthermore, whether sUA is an independent risk factor of hard endpoints remains unclear and has been further complicated by the interaction of sUA levels and renal function. Thus, the role of sUA in patients and its influence on their CV system has not been discovered. The superiority of XOI over uricosuric agents is due to potential inhibition of ROS production and its antioxidant effect. The treatment target based on the solubility of UA may need to be reconsidered, especially since data from PAMELA study identified a lower clinically meaningful cut-off level of sUA, i.e. $<5 \mathrm{mg} / \mathrm{dL}$, and even lower for women. Uptill now a patients' sUA level is not taken into consideration in the algorithm for assessing their total $\mathrm{CV}$ risk. Last, but by no means least, there is no evidence to support the treatment of asymptomatic $\mathrm{HU}$, although, a large body of evidence does show the beneficial effect of ULT on CV results. In this light, when $\mathrm{HU}$ accompanies other $\mathrm{CV}$ risk factors, therapy with XOI should at least be considered.

\section{Most relevant recommendations: The take home message for the clinical practitioners}

A remarkable number of epidemiological studies have demonstrated that $\mathrm{HU}$ is strongly related to increased CV risk and predicts CV mortality and morbidity in such diseases as hypertension or diabetes. The fact that there is a significant increase in the onset of newly diagnosed hypertension, metabolic syndrome in healthy patients with elevated levels of sUA, its role has been proved to be an independent risk factor in CV patients. Therefore, all considerations presented, point to the need for greater attention to monitoring sUA levels when diagnosing patients, not only from a rheumatological standpoint but also regarding $\mathrm{CV}$ and renal risk, including eGFR measurements $[4,195]$. This will play a key role in the prevention of CVD and improve future treatment strategies. The need for active screening of $\mathrm{CV}$ risk factors in patients who had been diagnosed with gout is highly recommended both by the ACR and The
European League Against Rheumatism (EULAR) [169, 196, 197].

In conclusion, we would like to summarize our recommendations which should be helpful to clinicians treating with patients suffering from $\mathrm{HU}$ who also have a high CV risk:

- All patients with HU should be informed about pharmacological and epidemiological factors influencing $\mathrm{HU}$, comorbidities, and the $\mathrm{CV}$ risk factors.

- All patients should receive precise information about required lifestyle modification, modification to their diet, a need for weight loss if necessary, and strict adherence to recommended treatment

- Physical activity increase to a moderate level is strongly recommended.

- As we have established that the sUA level in $\mathrm{CV}$ patients contributes to the identification of patients at high risk, they should be regularly monitored.

- Both patients and physicians, including primary care physicians, should strive to obtain and maintain lifelong sUA levels lower than $6 \mathrm{mg} / \mathrm{dL}$. In cardiovascular patients the target level should be $<5 \mathrm{mg} / \mathrm{dL}$.

- As soon as a diagnosis of HU is reached, ULT with XOI should be prescribed. Consider starting allopurinol $100 \mathrm{mg}$ daily, then titrate to 300-600 mg daily to reach the targets.

- Once the desired sUA target is achieved, the dose of ULT should be maintained indefinitely and the patient' sUA level should be monitored twice a year.

- A dosage of allopurinol of 300-600 mg/daily is recommended. If it is not tolerated by the patient or desired target of sUA is not reached, the combined therapy of allopurinol + uricosuric/lesinurad, should be prescribed.

- In patients with renal impairment, the allopurinol dosage should be adjusted to eGFR.

- In patients with HU receiving diuretics, treatment modification is needed.

- Febuxostat should be avoided, especially in patients with a high CV risk.

Conflict of interest: Claudio Borghi: has received honoraria for participation as speaker in national/ /international meetings from Menarini International, Berlin-Chemie, Servier, Takeda, Astellas, Novartis, Grunenthal, Sanofi; he is a member of Advisory Boards for: Menarini, Servier, Novartis, Grunenthal, BMS, Alfasigma; Andrzej Tykarski: has received honoraria for participation 
as speaker in national/international meetings from Servier, Berlin-Chemie Menarini, Egis, Biofarm, Krka, Gedeon Richter, Merck; Krystyna Widecka: report no conflict of interest; Krzysztof J. Filipiak: has received honoraria for participation as speaker in national/international meetings from Egis and Berlin-Chemie/Menarini; Justyna Domienik-Karłowicz: has received consulting honoraria from Egis; Katarzyna Kostka-Jeziorny: has received honoraria for participation as speaker in national/ /international meetings from Egis; Albert Varga: report no conflict of interest; Milosz Jaguszewski: has received speaker or consultation fees from Boheringer Ingelheim, Servier, Sandoz, Pfizer, Egis; Krzysztof Narkiewicz: has received honoraria or consultation fees from Servier, Krka, Berlin-Chemie/Menarini, Egis, Sandoz, Idorsia, Medtronic, Mylan, Polpharma, Adamed, Gedeon Richter; Giuseppe Mancia: has received honoraria for participation as speaker or chairman in national/ /international meetings from: Abbott, Boehringer Ingelheim, Daichi Sankyo, Ferrer, Medtronic, Menarini, Merck, Novartis, Recordati, Sanofi, Servier.

\section{References}

1. Kuo CF, Grainge MJ, Zhang W, et al. Global epidemiology of gout: prevalence, incidence and risk factors. Nat Rev Rheumatol. 2015; 11(11): 649-662, doi: 10.1038/nrrheum.2015.91, indexed in Pubmed: 26150127.

2. Zhu Y, Pandya BJ, Choi HK. Comorbidities of gout and hyperuricemia in the US general population: NHANES 2007-2008. Am J Med. 2012; 125(7): 679-687.e1, doi: 10.1016/j.amjmed.2011.09.033, indexed in Pubmed: 22626509.

3. Bardin T, Richette P. Impact of comorbidities on gout and hyperuricaemia: an update on prevalence and treatment options. BMC Med. 2017; 15(1): 123, doi: 10.1186/s12916-017-0890-9, indexed in Pubmed: 28669352.

4. Borghi C, Rosei EA, Bardin T, et al. Serum uric acid and the risk of cardiovascular and renal disease. J Hypertens. 2015; 33(9): 1729-1741, doi:10.1097/HJH.0000000000000701, indexed in Pubmed: 26136207.

5. Conen D, Wietlisbach V, Bovet P, et al. Prevalence of hyperuricemia and relation of serum uric acid with cardiovascular risk factors in a developing country. BMC Public Health. 2004; 4: 9, doi: 10.1186/1471-2458-4-9, indexed in Pubmed: 15043756.

6. Qiu L, Cheng Xq, Wu J, et al. Prevalence of hyperuricemia and its related risk factors in healthy adults from Northern and Northeastern Chinese provinces. BMC Public Health. 2013; 13: 664, doi: 10.1186/1471-2458-13-664, indexed in Pubmed: 23866159.

7. Feig DI, Kang DH, Johnson RJ. Uric acid and cardiovascular risk. N Engl J Med. 2008; 359(17): 1811-1821, doi: 10.1056/ NEJMra0800885, indexed in Pubmed: 18946066.

8. Johnson RJ, Titte S, Cade JR, et al. Uric acid, evolution and primitive cultures. Semin Nephrol. 2005; 25(1): 3-8, indexed in Pubmed: 15660328.

9. Struthers A, Shearer F. Allopurinol: novel indications in cardiovascular disease. Heart. 2012; 98(21): 1543-1545, doi: 10.1136/ /heartjnl-2012-302249, indexed in Pubmed: 22801998.

10. Ragab G, Elshahaly M, Bardin T. Gout: An old disease in new perspective: a review. J Adv Res. 2017; 8(5): 495-511, doi: 10.1016/j. jare.2017.04.008, indexed in Pubmed: 28748116.
11. Perez-Ruiz F, Calabozo M, Pijoan JI, et al. Effect of urate-lowering therapy on the velocity of size reduction of tophi in chronic gout. Arthritis Rheum. 2002; 47(4): 356-360, doi: 10.1002/ /art.10511, indexed in Pubmed: 12209479.

12. McCarty DJ. A historical note: Leeuwenhoek's description of crystals from a gouty tophus. Arthritis Rheum. 1970; 13(4): 414-418, indexed in Pubmed: 4914047.

13. Lin KC, Lin HY, Chou P. The interaction between uric acid level and other risk factors on the development of gout among asymptomatic hyperuricemic men in a prospective study. J Rheumatol. 2000; 27(6): 1501-1505.

14. Hall AP, Barry PE, Dawber TR, et al. Epidemiology of gout and hyperuricemia. A long-term population study. Am J Med. 1967; 42(1): 27-37, indexed in Pubmed: 6016478.

15. Schlesinger N, Norquist JM, Watson DJ. Serum urate during acute gout. J Rheumatol. 2009; 36(6): 1287-1289, doi: 10.3899/ jrheum.080938, indexed in Pubmed: 19369457.

16. Logan JA, Morrison E, McGill PE. Serum uric acid in acute gout. Ann Rheum Dis. 1997; 56(11): 696-697, indexed in Pubmed: 9462177.

17. Forbess LJ, Fields TR. The broad spectrum of urate crystal deposition: unusual presentations of gouty tophi. Semin $\mathrm{Ar}$ thritis Rheum. 2012; 42(2): 146-154, doi: 10.1016/j.semarthrit.2012.03.007, indexed in Pubmed: 22522111.

18. Martillo MA, Nazzal L, Crittenden DB. The crystallization of monosodium urate. Curr Rheumatol Rep. 2014; 16(2): 400, doi: 10.1007/s11926-013-0400-9, indexed in Pubmed: 24357445.

19. Nakagawa $\mathrm{T}, \mathrm{Hu} \mathrm{H}, \mathrm{Zharikov} \mathrm{S}$, et al. A causal role for uric acid in fructose-induced metabolic syndrome. Am J Physiol Renal Physiol. 2006; 290(3): F625-F631, doi: 10.1152/ajprenal.00140.2005, indexed in Pubmed: 16234313.

20. Enomoto A, Kimura H, Chairoungdua A, et al. Molecular identification of a renal urate anion exchanger that regulates blood urate levels. Nature. 2002; 417(6887): 447-452, doi: 10.1038/ nature742, indexed in Pubmed: 12024214.

21. Borghi $\mathrm{C}$. The management of hyperuricemia: back to the pathophysiology of uric acid. Curr Med Res Opin. 2017; 33(sup3): 1-4, doi: 10.1080/03007995.2017.1378502, indexed in Pubmed: 28952386.

22. de Oliveira EP, Burini RC. High plasma uric acid concentration: causes and consequences. Diabetol Metab Syndr. 2012; 4: 12, doi: 10.1186/1758-5996-4-12, indexed in Pubmed: 22475652.

23. Prasad M, Matteson EL, Herrmann J, et al. Uric acid is associated with inflammation, coronary microvascular dysfunction, and adverse outcomes in postmenopausal women. Hypertension. 2017; 69(2): 236-242, doi: 10.1161/HYPERTENSIONAHA.116.08436, indexed in Pubmed: 27993955.

24. Farquharson CA, et al. Allopurinol improves endothelial dysfunction in chronic heart failure. Circulation. 2002; 106(2): 221-226.

25. Watanabe S, Kang DH, Feng L, et al. Uric acid, hominoid evolution, and the pathogenesis of salt-sensitivity. Hypertension. 2002; 40(3): 355-360, indexed in Pubmed: 12215479.

26. Lin $\mathrm{C}$, Zhang $\mathrm{Pu}$, Xue $\mathrm{Y}$, et al. Link of renal microcirculatory dysfunction to increased coronary microcirculatory resistance in hypertensive patients. Cardiol J. 2017; 24(6): 623-632, doi: 10.5603/CJ.a2017.0074, indexed in Pubmed: 28653312.

27. Mazzali M, Hughes J, Kim YG, et al. Elevated uric acid increases blood pressure in the rat by a novel crystal-independent mechanism. Hypertension. 2001; 38(5): 1101-1106, indexed in Pubmed: 11711505.

28. Kang DH, Park SK, Lee IK, et al. Uric acid-induced C-reactive protein expression: implication on cell proliferation and nitric oxide production of human vascular cells. J Am Soc Nephrol. 2005; 16(12): 3553-3562, doi: 10.1681/ASN.2005050572, indexed in Pubmed: 16251237.

29. Corry DB, Eslami P, Yamamoto K, et al. Uric acid stimulates vascular smooth muscle cell proliferation and oxidative stress via the vascular renin-angiotensin system. J Hypertens. 2008; 26(2): 269-275, doi: 10.1097/HJH.0b013e3282f240bf, indexed in Pubmed: 18192841. 
30. Kang DH, Han L, Ouyang X, et al. Uric acid causes vascular smooth muscle cell proliferation by entering cells via a functional urate transporter. Am J Nephrol. 2005; 25(5): 425-433, doi: 10.1159/000087713, indexed in Pubmed: 16113518.

31. Feig DI, Nakagawa T, Karumanchi SA, et al. Hypothesis: Uric acid, nephron number, and the pathogenesis of essential hypertension. Kidney Int. 2004; 66(1): 281-287, doi: 10.1111/j.15231755.2004.00729.x, indexed in Pubmed: 15200435.

32. Lee JE, Kim YG, Choi YH, et al. Serum uric acid is associated with microalbuminuria in prehypertension. Hypertension. 2006; 47(5): 962-967, doi: 10.1161/01.HYP.0000210550.97398.c2, indexed in Pubmed: 16520402.

33. Iseki K, Oshiro S, Tozawa M, et al. Significance of hyperuricemia on the early detection of renal failure in a cohort of screened subjects. Hypertens Res. 2001; 24(6): 691-697, indexed in Pubmed: 11768729.

34. Rosolowsky ET, Ficociello LH, Maselli NJ, et al. High-normal serum uric acid is associated with impaired glomerular filtration rate in nonproteinuric patients with type 1 diabetes. Clin J Am Soc Nephrol. 2008; 3(3): 706-713, doi: 10.2215/CJN.04271007, indexed in Pubmed: 18272826.

35. Furukawa S, Fujita T, Shimabukuro M, et al. Increased oxidative stress in obesity and its impact on metabolic syndrome. J Clin Invest. 2004; 114(12): 1752-1761, doi: 10.1172/JCI21625, indexed in Pubmed: 15599400.

36. Fabbrini E, Serafini M, Baric IC, et al. Effect of plasma uric acid on antioxidant capacity, oxidative stress, and insulin sensitivity in obese subjects. Diabetes. 2014; 63(3): 976-981, doi: 10.2337/db13-1396.

37. Grassi D, Desideri G, Giacomantonio ADi, et al. Hyperuricemia and cardiovascular risk. High Blood Press Cardiovasc Prev. 2014; 21(4): 235-242, doi:10.1007/s40292-014-0046-3.

38. Reginato AM, Mount DB, Yang I, et al. The genetics of hyperuricaemia and gout. Nat Rev Rheumatol. 2012; 8(10): 610-621, doi:10.1038/nrrheum.2012.144, indexed in Pubmed: 22945592.

39. Kalousdian S, Fabsitz R, Havlik R, et al. Heritability of clinical chemistries in an older twin cohort: the NHLBI Twin Study. Genet Epidemiol. 1987; 4(1): 1-11, doi: 10.1002/gepi.1370040102, indexed in Pubmed: 3569874.

40. Ichida K, Matsuo H, Takada T, et al. Decreased extra-renal urate excretion is a common cause of hyperuricemia. Nat Commun. 2012; 3: 764, doi: 10.1038/ncomms1756, indexed in Pubmed: 22473008 .

41. Kleber ME, Delgado G, Grammer TB, et al. Uric acid and cardiovascular events: a mendelian randomization study. J Am Soc Nephrol. 2015; 26(11): 2831-2838, doi: 10.1681/ /ASN.2014070660, indexed in Pubmed: 25788527.

42. Hughes K, Flynn T, de Zoysa J, et al. Mendelian randomization analysis associates increased serum urate, due to genetic variation in uric acid transporters, with improved renal function. Kidney Int. 2014; 85(2): 344-351, doi: 10.1038/ki.2013.353, indexed in Pubmed: 24048376.

43. Mallamaci F, Testa A, Leonardis D, et al. A polymorphism in the major gene regulating serum uric acid associates with clinic SBP and the white-coat effect in a family-based study. J Hypertens. 2014; 32(8): 1621-1628, doi: 10.1097/HJH.0000000000000224, indexed in Pubmed: 24805955.

44. Parsa A, Brown E, Weir MR, et al. Genotype-based changes in serum uric acid affect blood pressure. Kidney Int. 2012; 81(5): 502 -507, doi: 10.1038/ki.2011.414, indexed in Pubmed: 22189840.

45. Major TJ, Dalbeth N, Stahl EA, et al. An update on the genetics of hyperuricaemia and gout. Nat Rev Rheumatol. 2018; 14(6): 341-353, doi: 10.1038/s41584-018-0004-x, indexed in Pubmed: 29740155.

46. Cannon PJ, Stason WB, Demartini FE, et al. Hyperuricemia in primary and renal hypertension. N Engl J Med. 1966; 275(9): 457-464, doi: 10.1056/NEJM196609012750902, indexed in Pubmed: 5917940.

47. Ford ES, Li C, Cook S, et al. Serum concentrations of uric acid and the metabolic syndrome among US children and adolescents. Circulation. 2007; 115(19): 2526-2532, doi: 10.1161/CIRCULATIONAHA.106.657627, indexed in Pubmed: 17470699.

48. Puig JG, Martínez MA. Hyperuricemia, gout and the metabolic syndrome. Curr Opin Rheumatol. 2008; 20(2): 187-191, doi: 10.1097/BOR.0b013e3282f4b1ed, indexed in Pubmed: 18349749.
49. Tuttle KR, Short RA, Johnson RJ. Sex differences in uric acid and risk factors for coronary artery disease. Am J Cardiol. 2001; 87(12): 1411-1414, indexed in Pubmed: 11397367.

50. Dehghan A, van Hoek M, Sijbrands EJG, et al. High serum uric acid as a novel risk factor for type 2 diabetes. Diabetes Care. 2008; 31(2) 361-362, doi: 10.2337/dc07-1276, indexed in Pubmed: 17977935.

51. Schretlen DJ, Inscore AB, Vannorsdall TD, et al. Serum uric acid and brain ischemia in normal elderly adults. Neurology. 2007; 69(14): 1418-1423, doi: 10.1212/01.wnl.0000277468.10236.f1, indexed in Pubmed: 17909154.

52. Lehto S, Niskanen L, Rönnemaa T, et al. Serum uric acid is a strong predictor of stroke in patients with non-insulin-dependent diabetes mellitus. Stroke. 1998; 29(3): 635-639, indexed in Pubmed: 9506605.

53. Yu KH, Kuo CF, Luo SF, et al. Risk of end-stage renal disease associated with gout: a nationwide population study. Arthritis Res Ther. 2012; 14(2): R83, doi: 10.1186/ar3806, indexed in Pubmed: 22513212.

54. Abbott RD, Brand FN, Kannel WB, et al. Gout and coronary heart disease: the Framingham Study. J Clin Epidemiol. 1988; 41(3): 237-242, indexed in Pubmed: 3339376.

55. De Vera MA, Rahman MM, Bhole V, et al. Independent impact of gout on the risk of acute myocardial infarction among elderly women: a population-based study. Ann Rheum Dis. 2010; 69(6): 1162-1164, doi: 10.1136/ard.2009.122770, indexed in Pubmed: 20124358.

56. Choi HK, Mount DB, Reginato AM. Pathogenesis of gout. Ann Intern Med. 2005; 143(7): 499-516, indexed in Pubmed: 16204163.

57. Feig DI, Johnson RJ. Hyperuricemia in childhood primary hypertension. Hypertension. 2003; 42(3): 247-252, doi: 10.1161/01. HYP.0000085858.66548.59, indexed in Pubmed: 12900431.

58. Nakagawa T, Tuttle KR, Short RA, et al. Hypothesis: fructose-induced hyperuricemia as a causal mechanism for the epidemic of the metabolic syndrome. Nat Clin Pract Nephrol. 2005; 1(2): 80-86, doi: 10.1038/ncpneph0019, indexed in Pubmed: 16932373.

59. Niskanen LK, Laaksonen DE, Nyyssönen K, et al. Uric acid level as a risk factor for cardiovascular and all-cause mortality in middle-aged men: a prospective cohort study. Arch Intern Med. 2004; 164(14): 1546-1551, doi: 10.1001/archinte.164.14.1546, indexed in Pubmed: 15277287.

60. Yan D, Wang J, Jiang F, et al. A causal relationship between uric acid and diabetic macrovascular disease in Chinese type 2 diabetes patients: A Mendelian randomization analysis. Int J Cardiol. 2016; 214: 194-199, doi: 10.1016/j.ijcard.2016.03.206, indexed in Pubmed: 27064641.

61. Kuwabara M, Borghi C, Cicero AFG, et al. Elevated serum uric acid increases risks for developing high LDL cholesterol and hypertriglyceridemia: A five-year cohort study in Japan. Int J Cardiol. 2018; 261: 183-188, doi: 10.1016/j.ijcard.2018.03.045, indexed in Pubmed: 29551256.

62. Borghi C, Desideri G. Urate-Lowering drugs and prevention of cardiovascular disease: the emerging role of xanthine oxidase inhibition. Hypertension. 2016; 67(3): 496-498, doi: 10.1161/HY PERTENSIONAHA.115.06531, indexed in Pubmed: 26865197.

63. Bove M, Cicero AF, Veronesi M, et al. An evidence-based review on urate-lowering treatments: implications for optimal treatment of chronic hyperuricemia. Vasc Health Risk Manag. 2017; 13: 23-28, doi: 10.2147/VHRM.S115080, indexed in Pubmed: 28223818.

64. Lurbe E, Torro MI, Alvarez-Pitti J, et al. Uric acid is linked to cardiometabolic risk factors in overweight and obese youths. J Hypertens. 2018; 36(9): 1840-1846, doi: 10.1097/ HJH.0000000000001814, indexed in Pubmed: 29916994.

65. Jalal DI, Chonchol M, Chen W, et al. Uric acid as a target of therapy in CKD. Am J Kidney Dis. 2013; 61(1): 134-146, doi: 10.1053/j.ajkd.2012.07.021, indexed in Pubmed: 23058478.

66. Shadick NA, Kim R, Weiss S, et al. Effect of low level lead exposure on hyperuricemia and gout among middle aged and elderly men: the normative aging study. J Rheumatol. 2000; 27(7): 1708-1712, indexed in Pubmed: 10914856.

67. Zhu Y, Pandya BJ, Choi HK. Prevalence of gout and hyperuricemia in the US general population: the National Health and Nutrition Examination Survey 2007-2008. Arthritis Rheum. 2011; 63(10): 3136-3141, doi: 10.1002/art.30520, indexed in Pubmed: 21800283.

68. Yü TF, Berger L, Dorph DJ, et al. Renal function in gout. V. Factors influencing the renal hemodynamics. Am J Med. 1979; 67(5): 766-771, indexed in Pubmed: 507087. 
69. Tykarski A. Evaluation of renal handling of uric acid in essential hypertension: hyperuricemia related to decreased urate secretion. Nephron. 1991; 59(3): 364-368, doi: 10.1159/000186593, indexed in Pubmed: 1758523.

70. Messerli FH, Frohlich ED, Dreslinski GR, et al. Serum uric acid in essential hypertension: an indicator of renal vascular involvement. Ann Intern Med. 1980; 93(6): 817-821, indexed in Pubmed: 7447188.

71. Alper AB, Chen W, Yau L, et al. Childhood uric acid predicts adult blood pressure: the Bogalusa Heart Study. Hypertension. 2005; 45(1): 34-38, doi: 10.1161/01.HYP.0000150783.79172.bb, indexed in Pubmed: 15569853.

72. Dyer AR, Liu K, Walsh M, et al. Ten-year incidence of elevated blood pressure and its predictors: the CARDIA study. Coronary Artery Risk Development in (Young) Adults. J Hum Hypertens. 1999; 13(1): 13-21, indexed in Pubmed: 9928747.

73. Forman JP, Choi H, Curhan GC. Plasma uric acid level and risk for incident hypertension among men. J Am Soc Nephrol. 2007; 18(1): 287-292, doi: 10.1681/ASN.2006080865, indexed in Pubmed: 17167112 .

74. Hunt SC, Stephenson SH, Hopkins PN, et al. Predictors of an increased risk of future hypertension in Utah. A screening analysis. Hypertension. 1991; 17(6_pt_2): 969-976, doi: 10.1161/01. hyp.17.6.969.

75. Imazu M, Yamamoto H, Toyofuku M, et al. Hyperinsulinemia for the development of hypertension: data from the Hawaii-Los Angeles-Hiroshima Study. Hypertens Res. 2001; 24(5): 531-536, indexed in Pubmed: 11675947.

76. Jossa F, Farinaro E, Panico S, et al. Serum uric acid and hypertension: the Olivetti heart study. J Hum Hypertens. 1994; 8(9): 677-681, indexed in Pubmed: 7807497.

77. Krishnan E, Kwoh CK, Schumacher HR, et al. Hyperuricemia and incidence of hypertension among men without metabolic syndrome. Hypertension. 2007; 49(2): 298-303, doi: 10.1161/01. HYP.0000254480.64564.b6, indexed in Pubmed: 17190877.

78. Masuo K, Kawaguchi H, Mikami H, et al. Serum uric acid and plasma norepinephrine concentrations predict subsequent weight gain and blood pressure elevation. Hypertension. 2003; 42(4): 474-480, doi: 10.1161/01.HYP.0000091371.53502.D3, indexed in Pubmed: 12953019.

79. Mellen P, Bleyer A, Erlinger T, et al. Serum Uric Acid Predicts Incident Hypertension in a Biethnic Cohort. Hypertension. 2006; 48(6): 1037-1042, doi: 10.1161/01.hyp.0000249768.26560.66.

80. Nagahama K, Inoue T, Iseki K, et al. Hyperuricemia as a predictor of hypertension in a screened cohort in Okinawa, Japan. Hypertension Res. 2004; 27(11): 835-841, doi: 10.1291/ /hypres.27.835.

81. Taniguchi Y, Hayashi T, Tsumura K, et al. Serum uric acid and the risk for hypertension and Type 2 diabetes in Japanese men: The Osaka Health Survey. J Hypertens. 2001; 19(7): 1209-1215, indexed in Pubmed: 11446710.

82. Kang DH, Nakagawa T, Feng L, et al. A role for uric acid in the progression of renal disease. J Am Soc Nephrol. 2002; 13(12): 2888-2897, indexed in Pubmed: 12444207.

83. Syamala S, Li J, Shankar A. Association between serum uric acid and prehypertension among US adults. J Hypertens. 2007; 25(8): 1583-1589, doi: 10.1097/HJH.0b013e32813aeb6c, indexed in Pubmed: 17620953.

84. Grayson PC, Kim SY, LaValley M, et al. Hyperuricemia and incident hypertension: a systematic review and meta-analysis. Arthritis Care Res (Hoboken). 2011; 63(1): 102-110, doi: 10.1002/ /acr.20344, indexed in Pubmed: 20824805.

85. Bombelli M, Ronchi I, Volpe M, et al. Prognostic value of serum uric acid: new-onset in and out-of-office hypertension and long-term mortality. J Hypertens. 2014; 32(6): 1237-1244, doi: 10.1097/HJH.0000000000000161, indexed in Pubmed: 24675682

86. Perlstein TS, Gumieniak O, Williams GH, et al. Uric acid and the development of hypertension: the normative aging study. Hypertension. 2006; 48(6): 1031-1036, doi: 10.1161/01. HYP.0000248752.08807.4c, indexed in Pubmed: 17060508.

87. Forman JP, Choi H, Curhan GC. Uric acid and insulin sensitivity and risk of incident hypertension. Arch Intern Med. 2009, 169(2): 155-162, doi: 10.1001/archinternmed.2008.521, indexed in Pubmed: 19171812.
88. Zhang W, Sun K, Yang Y, et al. Plasma uric acid and hypertension in a Chinese community: prospective study and metaanalysis. Clin Chem. 2009; 55(11): 2026-2034, doi: 10.1373/ /clinchem.2009.124891, indexed in Pubmed: 19729471.

89. Shankar A, Klein R, Klein BEK, et al. The association between serum uric acid level and long-term incidence of hypertension: Population-based cohort study. J Hum Hypertens. 2006; 20(12): 937-945, doi: 10.1038/sj.jhh.1002095, indexed in Pubmed: 17024135

90. Sundström J, Sullivan L, D'Agostino RB, et al. Relations of serum uric acid to longitudinal blood pressure tracking and hypertension incidence. Hypertension. 2005; 45(1): 28-33, doi: 10.1161/01. HYP.0000150784.92944.9a, indexed in Pubmed: 15569852.

91. Kuwabara M, Hisatome I, Niwa K, et al. Uric acid is a strong risk marker for developing hypertension from prehypertension: a 5-year Japanese Cohort Study. Hypertension. 2018; 71(1): 78-86, doi: 10.1161/HYPERTENSIONAHA.117.10370, indexed in Pubmed: 29203632.

92. Norvik JV, et al. Overweight modifies the longitudinal association between uric acid and some components of the metabolic syndrome: The Tromso Study. BMC Cardiovasc Disord. 2016; 16: 85.

93. Juraschek SP, Kovell LC, Miller ER, et al. Association of kidney disease with prevalent gout in the United States in 19881994 and 2007-2010. Semin Arthritis Rheum. 2013; 42(6): 551-561, doi: 10.1016/j.semarthrit.2012.09.009, indexed in Pubmed: 23312548.

94. Jing J, Kielstein JT, Schultheiss UT, et al. Prevalence and correlates of gout in a large cohort of patients with chronic kidney disease: the German Chronic Kidney Disease (GCKD) study Nephrol Dial Transplant. 2015; 30(4): 613-621, doi: 10.1093/ndt/ gfu352, indexed in Pubmed: 25395390.

95. Johnson RJ, Nakagawa T, Jalal D, et al. Uric acid and chronic kidney disease: which is chasing which? Nephrol Dial Transplant. 2013; 28(9): 2221-2228, doi: 10.1093/ndt/gft029, indexed in Pubmed: 23543594.

96. Hsu Cy, Iribarren C, McCulloch CE, et al. Risk factors for endstage renal disease: 25-year follow-up. Arch Intern Med. 2009; 169(4): 342-350, doi: 10.1001/archinternmed.2008.605, indexed in Pubmed: 19237717.

97. Myllymäki J, Honkanen T, Syrjänen J, et al. Uric acid correlates with the severity of histopathological parameters in IgA nephropathy. Nephrol Dial Transplant. 2005; 20(1): 89-95, doi: 10.1093/ /ndt/gfh584, indexed in Pubmed: 15572382.

98. Liu P, Chen Y, Wang B, et al. Allopurinol treatment improves renal function in patients with type 2 diabetes and asymptomatic hyperuricemia: 3-year randomized parallel-controlled study. Clin Endocrinol (Oxf). 2015; 83(4): 475-482, doi: 10.1111/cen.12673, indexed in Pubmed: 25400252.

99. Hart A, Jackson S, Kasiske BL, et al. Uric acid and allograft loss from interstitial fibrosis/tubular atrophy: post hoc analysis from the angiotensin II blockade in chronic allograft nephropathy trial. Transplantation. 2014; 97(10): 1066-1071, doi: 10.1097/01. TP.0000440952.29757.66, indexed in Pubmed: 24503762.

100. Bellomo G, Venanzi S, Verdura C, et al. Association of uric acid with change in kidney function in healthy normotensive individuals. Am J Kidney Dis. 2010; 56(2): 264-272, doi: 10.1053/j. ajkd.2010.01.019, indexed in Pubmed: 20385436.

101. Obermayr RP, Temml C, Knechtelsdorfer M, et al. Predictors of new-onset decline in kidney function in a general middle-european population. Nephrol Dial Transplant. 2008; 23(4): 1265-1273, doi: 10.1093/ndt/gfm790, indexed in Pubmed: 18039642.

102. Bos MJ, Koudstaal PJ, Hofman A, et al. Uric acid is a risk factor for myocardial infarction and stroke: the Rotterdam study. Stroke. 2006; 37(6): 1503-1507, doi: 10.1161/01.STR.0000221716.55088.d4, indexed in Pubmed: 16675740.

103. Ruggiero C, Cherubini A, Lauretani F, et al. Uric acid and dementia in community-dwelling older persons. Dement Geriatr Cogn Disord. 2009; 27(4): 382-389, doi: 10.1159/000210040, indexed in Pubmed: 19339776.

104. Lu Na, Dubreuil M, Zhang Y, et al. Gout and the risk of Alzheimer's disease: a population-based, BMI-matched cohort study. Ann Rheum Dis. 2016; 75(3): 547-551, doi: 10.1136/annrheumdis-2014-206917, indexed in Pubmed: 25739830.

105. Yan DD, Wang J, Hou XH, et al. Association of serum uric acid levels with osteoporosis and bone turnover markers in a Chi- 
nese population. Acta Pharmacol Sin. 2018; 39(4): 626-632, doi: 10.1038/aps.2017.165, indexed in Pubmed: 29239351.

106. Stack AG, Hanley A, Casserly LF, et al. Independent and conjoint associations of gout and hyperuricaemia with total and cardiovascular mortality. QJM. 2013; 106(7): 647-658, doi: 10.1093/qjmed/ /hct083, indexed in Pubmed: 23564632.

107. Ioachimescu AG, Brennan DM, Hoar BM, et al. Serum uric acid is an independent predictor of all-cause mortality in patients at high risk of cardiovascular disease: a preventive cardiology information system (PreCIS) database cohort study. Arthritis Rheum. 2008; 58(2): 623-630, doi: 10.1002/art.23121, indexed in Pubmed: 18240236.

108. Choi HK, Curhan G. Independent impact of gout on mortality and risk for coronary heart disease. Circulation. 2007; 116(8): 894-900, doi:10.1161/CIRCULATIONAHA.107.703389, indexed in Pubmed: 17698728.

109. Kuo CF, See LC, Yu KH, et al. Significance of serum uric acid levels on the risk of all-cause and cardiovascular mortality. Rheumatology (Oxford). 2013; 52(1): 127-134, doi: 10.1093/rheumatology/kes223, indexed in Pubmed: 22923756.

110. Tamariz L, Harzand A, Palacio A, et al. Uric acid as a predictor of all-cause mortality in heart failure: a meta-analysis. Congest Heart Fail. 2011; 17(1): 25-30, doi: 10.1111/j.17517133.2011.00200.x, indexed in Pubmed: 21272224.

111. Thanassoulis G, Brophy JM, Richard H, et al. Gout, allopurinol use, and heart failure outcomes. Arch Intern Med. 2010; 170(15): 1358-1364, doi: 10.1001/archinternmed.2010.198, indexed in Pubmed: 20696962.

112. Krishnan E, Pandya BJ, Lingala B, et al. Hyperuricemia and untreated gout are poor prognostic markers among those with a recent acute myocardial infarction. Arthritis Res Ther. 2012; 14(1): R10, doi: 10.1186/ar3684, indexed in Pubmed: 22251426.

113. Tscharre M, Herman R, Rohla M, et al. Uric acid is associated with long-term adverse cardiovascular outcomes in patients with acute coronary syndrome undergoing percutaneous coronary intervention. Atherosclerosis. 2018; 270: 173-179, doi: 10.1016/j. atherosclerosis.2018.02.003, indexed in Pubmed: 29432935.

114. Andrés M, Quintanilla MA, Sivera F, et al. Silent monosodium urate crystal deposits are associated with severe coronary calcification in asymptomatic hyperuricemia: an exploratory study. Arthritis Rheumatol. 2016; 68(6): 1531-1539, doi: 10.1002/ /art.39581, indexed in Pubmed: 26748935.

115. Holme I, Aastveit AH, Hammar N, et al. Uric acid and risk of myocardial infarction, stroke and congestive heart failure in 417,734 men and women in the Apolipoprotein MOrtality RISk study (AMORIS). J Intern Med. 2009; 266(6): 558-570, doi: 10.1111/j.13652796.2009.02133.x, indexed in Pubmed: 19563390.

116. Crosta F, Occhiuzzi U, Passalacqua G, et al. Association Between the Serum Uric Acid Levels and Lacunar Infarcts in the Elderly. J Mol Neurosci. 2018; 65(3): 385-390, doi: 10.1007/s12031-0181096-0, indexed in Pubmed: 29974380.

117. White WB, Saag KG, Becker MA, et al. CARES Investigators. Cardiovascular safety of febuxostat or allopurinol in patients with gout. N Engl J Med. 2018; 378(13): 1200-1210, doi: 10.1056/ /NEJMoa1710895, indexed in Pubmed: 29527974.

118. MacIsaac RL, Salatzki J, Higgins P, et al. Allopurinol and cardiovascular outcomes in adults with hypertension. Hypertension. 2016; 67(3): 535-540, doi: 10.1161/HYPERTENSIONAHA.115.06344, indexed in Pubmed: 26865199.

119. Goicoechea M, Garcia de Vinuesa S, Verdalles U, et al. Allopurinol and progression of CKD and cardiovascular events: longterm follow-up of a randomized clinical trial. Am J Kidney Dis. 2015; 65(4): 543-549, doi: 10.1053/j.ajkd.2014.11.016, indexed in Pubmed: 25595565.

120. Becker MA, Schumacher HR, Espinoza LR, et al. The uratelowering efficacy and safety of febuxostat in the treatment of the hyperuricemia of gout: the CONFIRMS trial. Arthritis Res Ther. 2010; 12(2): R63, doi: 10.1186/ar2978, indexed in Pubmed: 20370912.

121. Bredemeier M, Lopes LM, Eisenreich MA, et al. Xanthine oxidase inhibitors for prevention of cardiovascular events: a systematic review and meta-analysis of randomized controlled trials. BMC Cardiovasc Disord. 2018; 18(1): 24, doi: 10.1186/s12872018-0757-9, indexed in Pubmed: 29415653.
122. Frampton JE. Febuxostat: a review of its use in the treatment of hyperuricaemia in patients with gout. Drugs. 2015; 75(4): 427-438, doi: 10.1007/s40265-015-0360-7, indexed in Pubmed: 25724536.

123. Kim SC, Neogi T, Kang EHa, et al. Cardiovascular risks of probenecid versus allopurinol in older patients with gout. J Am Coll Cardiol. 2018; 71(9): 994-1004, doi: 10.1016/j. jacc.2017.12.052, indexed in Pubmed: 29496000.

124. Szwejkowski BR, Gandy SJ, Rekhraj S, et al. Allopurinol reduces left ventricular mass in patients with type 2 diabetes and left ventricular hypertrophy. J Am Coll Cardiol. 2013; 62(24): 2284-2293, doi: 10.1016/j.jacc.2013.07.074, indexed in Pubmed: 23994420.

125. Akkineni R, Tapp S, Tosteson ANA, et al. Treatment of asymptomatic hyperuricemia and prevention of vascular disease: a decision analytic approach. J Rheumatol. 2014; 41(4): 739-748, doi: 10.3899/jrheum.121231, indexed in Pubmed: 24584921.

126. Zhang T, Pope JE. Cardiovascular effects of urate-lowering therapies in patients with chronic gout: a systematic review and meta-analysis. Rheumatology (Oxford). 2017; 56(7): 1144-1153, doi: 10.1093/rheumatology/kex065, indexed in Pubmed: 28379501.

127. Richette P, Latourte A, Bardin T. Cardiac and renal protective effects of urate-lowering therapy. Rheumatology (Oxford). 2018; 57(suppl 1): i47-i50, doi: 10.1093/rheumatology/kex432, indexed in Pubmed: 29272510.

128. Wei Li, Mackenzie IS, Chen Y, et al. Impact of allopurinol use on urate concentration and cardiovascular outcome. $\mathrm{Br}$ J Clin Pharmacol. 2011; 71(4): 600-607, doi: 10.1111/j.1365 2125.2010.03887.x, indexed in Pubmed: 21395653.

129. Richette P, Perez-Ruiz F, Doherty M, et al. Improving cardiovascular and renal outcomes in gout: what should we target? Nat Rev Rheumatol. 2014; 10(11): 654-661, doi: 10.1038/nrrheum.2014.124, indexed in Pubmed: 25136785.

130. Okafor ON, Farrington K, Gorog DA. Allopurinol as a therapeutic option in cardiovascular disease. Pharmacol Ther. 2017; 172: 139-150, doi: 10.1016/j.pharmthera.2016.12.004, indexed in Pubmed: 27916655.

131. Perez-Ruiz F, Martínez-Indart L, Carmona L, et al. Tophaceous gout and high level of hyperuricaemia are both associated with increased risk of mortality in patients with gout. Ann Rheum Dis. 2014; 73(1): 177-182, doi: 10.1136/annrheumdis-2012-202421, indexed in Pubmed: 23313809.

132. Pacher P, Nivorozhkin A, Szabó C. Therapeutic effects of xanthine oxidase inhibitors: renaissance half a century after the discovery of allopurinol. Pharmacol Rev. 2006; 58(1): 87-114, doi: 10.1124/pr.58.1.6, indexed in Pubmed: 16507884.

133. Wei Li, Mackenzie IS, Chen Y, et al. Impact of allopurinol use on urate concentration and cardiovascular outcome. $\mathrm{Br}$ J Clin Pharmacol. 2011; 71(4): 600-607, doi: 10.1111/j.13652125.2010.03887.x, indexed in Pubmed: 21395653.

134. Wei L, Fahey T, Struthers AD, et al. Association between allopurinol and mortality in heart failure patients: a long-term follow-up study. Int J Clin Pract. 2009; 63(9): 1327-1333, doi: 10.1111/j.1742 1241.2009.02118.x, indexed in Pubmed: 19691616.

135. Dubreuil M, Zhu Y, Zhang Y, et al. Allopurinol initiation and all-cause mortality in the general population. Ann Rheum Dis. 2015; 74(7): 1368-1372, doi: 10.1136/annrheumdis-2014-205269, indexed in Pubmed: 24665118.

136. Noman A, Ang DSC, Ogston S, et al. Effect of high-dose allopurinol on exercise in patients with chronic stable angina: a randomised, placebo controlled crossover trial. Lancet. 2010; 375(9732): 2161-2167, doi: 10.1016/S0140-6736(10)60391-1, indexed in Pubmed: 20542554.

137. Rekhraj S, Gandy SJ, Szwejkowski BR, et al. High-dose allopurinol reduces left ventricular mass in patients with ischemic heart disease. J Am Coll Cardiol. 2013; 61(9): 926-932, doi: 10.1016/j. jacc.2012.09.066, indexed in Pubmed: 23449426.

138. Higgins P, Dawson J, Lees KR, et al. Xanthine oxidase inhibition for the treatment of cardiovascular disease: a systematic review and meta-analysis. Cardiovasc Ther. 2012; 30(4): 217-226, doi: 10.1111/j.1755-5922.2011.00277.x, indexed in Pubmed: 22099531.

139. George J, Carr E, Davies J, et al. High-dose allopurinol improves endothelial function by profoundly reducing vascular oxidative 
stress and not by lowering uric acid. Circulation. 2006; 114(23): 2508-2516, doi: 10.1161/CIRCULATIONAHA.106.651117, indexed in Pubmed: 17130343.

140. Givertz MM, Anstrom KJ, Redfield MM, et al. Effects of Xanthine Oxidase Inhibition in Hyperuricemic Heart Failure Patients: The Xanthine Oxidase Inhibition for Hyperuricemic Heart Failure Patients (EXACT-HF) Study. Circulation. 2015; 131(20): 1763-1771, doi: 10.1161/CIRCULATIONAHA.114.014536, indexed in Pubmed: 25986447.

141. Cleland JGF, Coletta AP, Clark AL. Clinical trials update from the Heart Failure Society of America meeting: FIX-CHF-4, selective cardiac myosin activator and OPT-CHF. Eur J Heart Fail. 2006; 8(7): 764-766, doi: 10.1016/j.ejheart.2006.10.001, indexed in Pubmed: 17049305.

142. Freudenberger RS, Schwarz RP, Brown J, et al. Rationale, design and organisation of an efficacy and safety study of oxypurinol added to standard therapy in patients with NYHA class III-IV congestive heart failure. Expert Opin Investig Drugs. 2004; 13(11): 1509-1516, doi: 10.1517/13543784.13.11.1509, indexed in Pubmed: 15500398

143. George J, Struthers A. The OPT-CHF (Oxypurinol Therapy for Congestive Heart Failure) trial: a question of dose. J Am Coll Cardiol. 2009; 53(25): 2405, doi: 10.1016/j.jacc.2008.07.076, indexed in Pubmed: 19539154.

144. Hare JM, Mangal B, Brown J, et al. Impact of oxypurinol in patients with symptomatic heart failure. Results of the OPT-CHF study. J Am Coll Cardiol. 2008; 51(24): 2301-2309, doi: 10.1016/j. jacc.2008.01.068, indexed in Pubmed: 18549913.

145. Beattie CJ, Fulton RL, Higgins P, et al. Allopurinol initiation and change in blood pressure in older adults with hypertension. Hypertension. 2014; 64(5): 1102-1107, doi: 10.1161/HYPERTENSIONAHA.114.03953, indexed in Pubmed: 25135183.

146. Feig DI, Soletsky B, Johnson RJ. Effect of allopurinol on blood pressure of adolescents with newly diagnosed essential hypertension: a randomized trial. JAMA. 2008; 300(8): 924-932, doi: 10.1001/jama.300.8.924, indexed in Pubmed: 18728266.

147. Agarwal V, Hans N, Messerli FH. Effect of allopurinol on blood pressure: a systematic review and meta-analysis. J Clin Hypertens (Greenwich). 2013; 15(6): 435-442, doi: 10.1111/j.17517176.2012.00701.x, indexed in Pubmed: 23730993.

148. Kostka-Jeziorny K, Uruski P, Tykarski A. Effect of allopurinol on blood pressure and aortic compliance in hypertensive patients. Blood Press. 2011; 20(2): 104-110, doi: 10.3109/08037051.2010. 532323, indexed in Pubmed: 21405957.

149. Khan F, George J, Wong K, et al. Allopurinol treatment reduces arterial wave reflection in stroke survivors. Cardiovasc Ther. 2008; 26(4): 247-252, doi: 10.1111/j.1755-5922.2008.00057.x, indexed in Pubmed: 19035875.

150. Soletsky B, Feig DI. Uric acid reduction rectifies prehypertension in obese adolescents. Hypertension. 2012; 60(5): 1148-1156, doi:10.1161/HYPERTENSIONAHA.112.196980, indexed in Pubmed: 23006736.

151. Borghi C, Omboni S, Reggiardo G, et al. Effects of the concomitant administration of xanthine oxidase inhibitors with zofenopril or other ACE-inhibitors in post-myocardial infarction patients: a meta-analysis of individual data of four randomized, doubleblind, prospective studies. BMC Cardiovasc Disord. 2018; 18(1): 112, doi: 10.1186/s12872-018-0800-x, indexed in Pubmed: 29866077.

152. Luk AJ, Levin GP, Moore EE, et al. Allopurinol and mortality in hyperuricaemic patients. Rheumatology (Oxford). 2009; 48(7): 804-806, doi:10.1093/rheumatology/kep069, indexed in Pubmed: 19447769

153. Ueno S, Hamada T, Taniguchi S, et al. Effect of antihypertensive drugs on uric acid metabolism in patients with hypertension: cross-sectional cohort study. Drug Res (Stuttg). 2016; 66(12): 628-632, doi: 10.1055/s-0042-113183, indexed in Pubmed: 27643410 .

154. Kai H, Ueda T, Uchiwa H, et al. Benefit of losartan/hydrochlorothiazide-fixed dose combination treatment for isolated morning hypertension: The MAPPY study. Clin Exp Hypertens. 2015; 37(6): 473-481, doi: 10.3109/10641963.2015.1013118, indexed in Pubmed: 25816110.

155. Matsumura K, Arima H, Tominaga M, et al. Effect of losartan on serum uric acid in hypertension treated with a diuretic: the COM-
FORT study. Clin Exp Hypertens. 2015; 37(3): 192-196, doi: 10.3109/10641963.2014.933968, indexed in Pubmed: 25051056.

156. Okamura K, Shirai K, Totake N, et al. Prospective direct comparison of antihypertensive effect and safety between highdose amlodipine or indapamide in hypertensive patients uncontrolled by standard doses of angiotensin receptor blockers and amlodipine. Clin Exp Hypertens. 2018; 40(2): 99-106, doi: 10.1080/10641963.2017.1334798, indexed in Pubmed: 28692311.

157. Derosa G, Maffioli P, Sahebkar A. Plasma uric acid concentrations are reduced by fenofibrate: A systematic review and metaanalysis of randomized placebo-controlled trials. Pharmacol Res. 2015; 102: 63-70, doi: 10.1016/j.phrs.2015.09.012, indexed in Pubmed: 26384444.

158. Milionis HJ, Kakafika AI, Tsouli SG, et al. Effects of statin treatment on uric acid homeostasis in patients with primary hyperlipidemia. Am Heart J. 2004; 148(4): 635-640, doi: 10.1016/j. ahj.2004.04.005, indexed in Pubmed: 15459594.

159. Chino Y, Samukawa Y, Sakai S, et al. SGLT2 inhibitor lowers serum uric acid through alteration of uric acid transport activity in renal tubule by increased glycosuria. Biopharm Drug Dispos. 2014; 35(7): 391-404, doi: 10.1002/bdd.1909, indexed in Pubmed: 25044127.

160. Kanji T, Gandhi M, Clase CM, et al. Urate lowering therapy to improve renal outcomes in patients with chronic kidney disease: systematic review and meta-analysis. BMC Nephrol. 2015; 16: 58, doi: 10.1186/s12882-015-0047-z, indexed in Pubmed: 25928556.

161. Goicoechea M, de Vinuesa SG, Verdalles U, et al. Effect of allopurinol in chronic kidney disease progression and cardiovascular risk. Clin J Am Soc Nephrol. 2010; 5(8): 1388-1393, doi: 10.2215/ /CJN.01580210, indexed in Pubmed: 20538833.

162. Su X, Xu B, Yan B, et al. Effects of uric acid-lowering therapy in patients with chronic kidney disease: A meta-analysis. PLoS One. 2017; 12(11): e0187550, doi: 10.1371/journal.pone.0187550, indexed in Pubmed: 29095953.

163. Siu YP, Leung KT, Tong MKH, et al. Use of allopurinol in slowing the progression of renal disease through its ability to lower serum uric acid level. Am J Kidney Dis. 2006; 47(1): 51-59, doi: 10.1053/j.ajkd.2005.10.006, indexed in Pubmed: 16377385.

164. Sampson AL, Singer RF, Walters GD. Uric acid lowering therapies for preventing or delaying the progression of chronic kidney disease. Cochrane Database Syst Rev. 2017; 10: CD009460, doi: 10.1002/14651858.CD009460.pub2, indexed in Pubmed: 29084343.

165. Levy GD, Rashid N, Niu F, et al. Effect of urate-lowering therapies on renal disease progression in patients with hyperuricemia. J Rheumatol. 2014; 41(5): 955-962, doi: 10.3899/jrheum.131159, indexed in Pubmed: 24692523.

166. Becker MA, Schumacher HR, Wortmann RL, et al. Febuxostat compared with allopurinol in patients with hyperuricemia and gout. N Engl J Med. 2005; 353(23): 2450-2461, doi: 10.1056/ NEJMoa050373, indexed in Pubmed: 16339094.

167. Whelton A, MacDonald PA, Chefo S, et al. Preservation of renal function during gout treatment with febuxostat: a quantitative study. Postgrad Med. 2013; 125(1): 106-114, doi: 10.3810/ pgm.2013.01.2626, indexed in Pubmed: 23391676.

168. Kimura K, Hosoya T, Uchida S, et al. Febuxostat Therapy for Patients With Stage 3 CKD and Asymptomatic Hyperuricemia: A Randomized Trial. Am J Kidney Dis. 2018 [Epub ahead of print], doi: 10.1053/j.ajkd.2018.06.028, indexed in Pubmed: 30177485.

169. Richette P, Doherty M, Pascual E, et al. 2016 updated EULAR evidence-based recommendations for the management of gout. Ann Rheum Dis. 2017; 76(1): 29-42, doi: 10.1136/annrheumdis-2016-209707, indexed in Pubmed: 27457514

170. Khanna D, Fitzgerald JD, Khanna PP, et al. 2012 American College of Rheumatology guidelines for management of gout. Part 1: systematic nonpharmacologic and pharmacologic therapeutic approaches to hyperuricemia. Arthritis Care Res (Hoboken). 2012; 64(10): 1431-1446, doi:10.1002/acr.21772, indexed in Pubmed: 23024028.

171. Hui M, Carr A, Cameron S, et al. The British Society for Rheumatology Guideline for the Management of Gout. Rheumatology. 2017; 56(7): 1246, doi:10.1093/rheumatology/kex250.

172. Roddy E, Packham J, Obrenovic K, et al. Management of gout by UK rheumatologists: a British Society for Rheumatology national audit. Rheumatology (Oxford). 2018; 57(5): 826-830, doi: 10.1093/ rheumatology/kex521, indexed in Pubmed: 29447370. 
173. Fotherby MD, Potter JF. Metabolic and orthostatic blood pressure responses to a low-sodium diet in elderly hypertensives. J Hum Hypertens. 1997; 11(6): 361-366, indexed in Pubmed: 9249230.

174. Singh JA, Reddy SG, Kundukulam J. Risk factors for gout and prevention: a systematic review of the literature. Curr Opin Rheumatol. 2011; 23(2): 192-202, doi: 10.1097/BOR.0b013e3283438e13, indexed in Pubmed: 21285714.

175. Jacob RA, Spinozzi GM, Simon VA, et al. Consumption of cherries lowers plasma urate in healthy women. J Nutr. 2003; 133(6): 1826-1829, doi:10.1093/jn/133.6.1826, indexed in Pubmed: 12771324 .

176. Schlesinger N. Dietary factors and hyperuricaemia. Curr Pharm Des. 2005; 11(32): 4133-4138, indexed in Pubmed: 16375734.

177. Richette P, Poitou C, Manivet P, et al. Weight Loss, Xanthine Oxidase, and Serum Urate Levels: A Prospective Longitudinal Study of Obese Patients. Arthritis Care Res (Hoboken). 2016; 68(7): 1036-1042, doi: 10.1002/acr.22798, indexed in Pubmed: 26844534 .

178. Chen JH, Wen CP, Wu SB, et al. Attenuating the mortality risk of high serum uric acid: the role of physical activity underused. Ann Rheum Dis. 2015; 74(11): 2034-2042, doi: 10.1136/annrheumdis-2014-205312, indexed in Pubmed: 25053714.

179. Borghi C, Perez-Ruiz F. Urate lowering therapies in the treatment of gout: a systematic review and meta-analysis. Eur Rev Med Pharmacol Sci. 2016; 20(5): 983-992, indexed in Pubmed: 27010159.

180. Neogi T, et al. Renal dosing of allopurinol results in suboptimal gout care. Ann Rheum Dis. 2017; 76(1): e1.

181. Stamp LK, O’Donnell JL, Zhang M, et al. Using allopurinol above the dose based on creatinine clearance is effective and safe in patients with chronic gout, including those with renal impairment. Arthritis Rheum. 2011; 63(2): 412-421, doi: 10.1002/art.30119, indexed in Pubmed: 21279998.

182. Rees F, Jenkins W, Doherty M. Patients with gout adhere to curative treatment if informed appropriately: proof-of-concept observational study. Ann Rheum Dis. 2013; 72(6): 826-830, doi: 10.1136/ annrheumdis-2012-201676, indexed in Pubmed: 22679303.

183. Ramasamy S, Korb-Wells C, Kannangara D, et al. Allopurinol Hypersensitivity: A Systematic Review of All Published Cases, 1950-2012. Drug Safety. 2013; 36(10): 953-980, doi: 10.1007/ /s40264-013-0084-0.

184. Hershfield MS, Callaghan JT, Tassaneeyakul W, et al. Clinical Pharmacogenetics Implementation Consortium guidelines for human leukocyte antigen-B genotype and allopurinol dosing. Clin Pharmacol Ther. 2013; 93(2): 153-158, doi: 10.1038/ /clpt.2012.209, indexed in Pubmed: 23232549.

185. Hande KR, Noone RM, Stone WJ. Severe allopurinol toxicity. Description and guidelines for prevention in patients with renal insufficiency. Am J Med. 1984; 76(1): 47-56.
186. Baldus S, Köster R, Chumley P, et al. Oxypurinol improves coronary and peripheral endothelial function in patients with coronary artery disease. Free Radic Biol Med. 2005; 39(9): 1184-1190, doi: 10.1016/j. freeradbiomed.2005.06.004, indexed in Pubmed: 16214034.

187. Guan W, Osanai T, Kamada T, et al. Effect of allopurinol pretreatment on free radical generation after primary coronary angioplasty for acute myocardial infarction. J Cardiovasc Pharmacol. 2003; 41(5): 699-705, doi: 10.1097/00005344-200305000-00005.

188. Baldus S, Müllerleile K, Chumley $\mathrm{P}$, et al. Inhibition of xanthine oxidase improves myocardial contractility in patients with ischemic cardiomyopathy. Free Radic Biol Med. 2006; 41(8): 1282-1288, doi: 10.1016/j.freeradbiomed.2006.07.010, indexed in Pubmed: 17015175.

189. Cappola T. Allopurinol improves myocardial efficiency in patients with idiopathic dilated cardiomyopathy. Circulation. 2001; 104(20): 2407-2411.

190. Scirè CA, Rossi C, Punzi L, et al. Change gout: how to deal with this. Curr Med Res Opin. 2018; 34(8): 1411-1417, doi: 10.1080/03007995.2018.1454896, indexed in Pubmed: 29553292

191. Saag KG, Fitz-Patrick D, Kopicko J, et al. Lesinurad combined with allopurinol: a randomized, double-blind, placebo-controlled study in gout patients with an inadequate response to standard-of-care allopurinol (a US-based study). Arthritis Rheumatol. 2017; 69(1) 203-212, doi: 10.1002/art.39840, indexed in Pubmed: 27564409.

192. Jones G, Panova E, Day R. Guideline development for the management of gout: role of combination therapy with a focus on lesinurad. Drug Des Devel Ther. 2017; 11: 3077-3081, doi: 10.2147/DDDT.S97959, indexed in Pubmed: 29123379.

193. Huneycutt E, Board C, Clements JN. Lesinurad, a selective URAT-1 inhibitor with a novel mechanism in combination with a xanthine oxidase inhibitor, for hyperuricemia associated with gout. J Pharm Pract. 2017 [Epub ahead of print]: 897190017734427, doi: 10.1177/0897190017734427, indexed in Pubmed: 28980503.

194. Deeks ED. Lesinurad: a review in hyperuricaemia of gout. Drugs Aging. 2017; 34(5): 401-410, doi: 10.1007/s40266-017-0461-y, indexed in Pubmed: 28425024.

195. Ruoff G, Edwards NL. Overview of serum uric acid treatment targets in gout: why less than $6 \mathrm{mg} / \mathrm{dL}$ ? Postgrad Med. 2016; 128(7): 706-715, doi: 10.1080/00325481.2016.1221732, indexed in Pubmed: 27558643.

196. FitzGerald JD, Mikuls TR, Neogi T, et al. Development of the American College of Rheumatology Electronic Clinical Quality Measures for Gout. Arthritis Care Res (Hoboken). 2018; 70(5): 659-671, doi: 10.1002/acr.23500, indexed in Pubmed: 29649348.

197. Khanna D, Fitzgerald JD, Khanna PP, et al. 2012 American College of Rheumatology guidelines for management of gout. Part 1: systematic nonpharmacologic and pharmacologic therapeutic approaches to hyperuricemia. Arthritis Care Res (Hoboken). 2012; 64(10): 1431-1446, doi: 10.1002/acr.21772, indexed in Pubmed: 23024028. 